\title{
Potential Vorticity Diagnosis of the Severe Convective Regime. Part III: The Hesston Tornado Outbreak
}

\author{
David A. Gold* AND John W. Nielsen-Gammon \\ Department of Atmospheric Sciences, Texas A\&M University, College Station, Texas
}

(Manuscript received 16 November 2006, in final form 4 June 2007)

\begin{abstract}
Nonlinear balance potential vorticity (PV) inversion is used to diagnose the sensitivity of the severe convective parameter space to the amplitude of a subsynoptic-scale PV anomaly on 13 March 1990, a day on which a significant tornado outbreak impacted the Great Plains. PV surgery is used to both amplify and remove the PV anomaly, and the contemporaneous impact on various convective parameters is subsequently quantified by using piecewise PV inversion to compute the changes in those parameters attributable to each PV alteration. It is found that amplifying the anomaly increases the CAPE by amounts typically ranging from $20 \%$ to $30 \%$ within the atmospheric columns experiencing the maximum PV increase. Ascent is increased slightly downshear of the PV anomaly, consistent with extant conceptual models governing synoptic-scale forcing for vertical motion. Amplifying the PV anomaly increases deep-layer shear over the southern half of the outbreak region and reduces storm-relative helicity over the northern half, primarily through changes in the estimated storm motion vector. Removing the anomaly produces complementary changes of the opposite sign. Thresholds of several commonly used convective parameters are chosen on the basis of prior empirical studies, and the horizontal displacement of these threshold contours produced by the PV alterations reveals that relatively modest subsynoptic-scale PV changes would not likely change the predominant convective mode during the Hesston outbreak.
\end{abstract}

\section{Introduction}

Given that many severe convective outbreaks are associated with mobile upper-level troughs, it is natural to ask whether the characteristics of severe convection are sensitive to the presence and intensity of such mobile troughs. Ensemble forecasts can be used to estimate the forecast uncertainties in environmental parameters governing convective mode and intensity, and eventually such operational ensembles will have sufficient resolution and realism to directly simulate the spectrum of convection and severe weather itself. Meanwhile, and even after such ensembles become routine, it is necessary for human forecasters to understand the direct relationship between the characteristics of severe convection and the various weather features contributing to the severe convective environment on any given day.

\footnotetext{
* Current affiliation: PPM Energy, Inc., Houston, Texas.
}

Corresponding author address: David A. Gold, P.O. Box 420898, Houston, TX 77242.

E-mail: dr_david_gold@earthlink.net
Gold and Nielsen-Gammon (2008a, hereafter Part I and Nielsen-Gammon and Gold (2008, hereafter Part II) established a balanced diagnostic framework for addressing issues such as this. To the extent that the severe convective regime (SCR) is adequately represented by balanced dynamics [defined broadly as in Davis et al. (1996) to include ageostrophic and vertical motions recoverable from potential vorticity $(\mathrm{PV})$ inversion], it is possible to explore the sensitivity of the SCR to trough structure and amplitude by using the same PV inversion techniques developed by Davis and Emanuel (1991) to successfully diagnose extratropical cyclogenesis.

To formulate the basic conceptual framework, Part II inverted idealized upper-level PV perturbations to determine their impact on convective available potential energy (CAPE). Larger changes in CAPE associated with a given perturbation imply a greater sensitivity of the SCR to such perturbations. Part II showed that, for the range of amplitudes considered, the environmental CAPE response is linear, such that local increases in PV near the tropopause produced proportional increases of CAPE. The magnitude of the CAPE response was sensitive to whether the modified PV was 
located in the upper troposphere or the lower stratosphere, with a stronger response in the former case. The background PV gradient within the jet stream caused the CAPE modification to be elongated in the along-jet direction.

In this paper, we modify the PV distribution associated with an observed upper-tropospheric trough in a realistic manner by using a scheme that seeks to reposition the PV contours in a way that is consistent with $\mathrm{PV}$ advection. This PV alteration simulates errors in the intensity of a shortwave trough proximate to the region of the 13 March 1990 tornado outbreak (henceforth, the "Hesston outbreak"). While the basic principles discussed in Part II carry over to a more realistic modification, the magnitude of the changes to the SCR are given a more quantitative grounding by associating them with common model forecast errors in the intensity of upper-level troughs.

Severe weather environments often include one or more poorly forecasted upper-tropospheric vorticity lobes or maxima rotating around a larger-scale slowly moving trough. The changes tested here correspond to first-order errors in such a trough: its complete absence or a doubling of its strength.

Besides CAPE, this paper also considers the response of various shear parameters and vertical motion to upper-level PV modifications. Both vertical motion and shear strongly govern the convective mode, so a careful diagnosis of the impact of PV changes on all these aspects of the environment is necessary for understanding the net impact of the intensity of an upperlevel short wave on the mode of severe convection. The reasons for the changes in vertical shear and vertical motion are found to be fairly general in nature, being founded on the nature of PV invertibility and the typical wind conditions surrounding developing Great Plains extratropical cyclones. Thus, this paper presents a diagnostic study that might serve as a representative event for understanding the nature of SCR changes associated with upper-level troughs.

While PV inversion is conceptually appealing, it provides an incomplete description of the effects of various weather features. Unbalanced responses may play an important role, as may the time-integrated effects of such features on the moisture distribution or evolution of convection. Part IV (Gold and Nielsen-Gammon $2008 \mathrm{~b}$ ) presents a diagnosis of a second severe weather event, both as a test of the generality of the conclusions of Part III as well as to enable an estimate of the importance of neglected or time-dependent processes through comparison with the model sensitivity study of Roebber et al. (2002).

Within section 2 of this paper, a synopsis of the Hess- ton outbreak is presented from the PV perspective. The diagnostic technique is summarized in section 3. In section 4, the trough is amplified and the effect on the convective parameters of the amplification is investigated. Then the second PV modification, removal of the shortwave trough in question, is described and the corresponding changes in the convective parameters are explored in section 5. An analysis technique, called threshold contour (TC) analysis, is introduced in section 6 to examine the potential impacts on convective mode that might be expected to occur under the PV modifications described in the previous sections. The paper concludes with a discussion of the results. A subsequent paper (Part IV) applies similar techniques to a separate event and compares the results to those obtained by Roebber et al. (2002) in a model-based diagnosis of the same event.

\section{A synoptic overview from the PV perspective}

The event studied here was on 13 March 1990, an outbreak that produced 56 tornadoes in six states from Texas to Illinois. Nearly half of the reported tornadoes were strong to violent (producing F2 or greater damage) on the Fujita (1981) scale, including two with pathlengths greater than 50 miles. This event was one of the most significant early-season outbreaks of severe convection ever to occur in the central plains (Davies et al. 1994). The most noteworthy events on this day were 1 ) a family of violent tornadoes in south-central Kansas, including an F5 tornado that struck the town of Hesston and 2) a large, long-track F4 tornado in south-central Nebraska. A few strong (F2 and F3) tornadoes also occurred in portions of Iowa and western Illinois along a synoptic-scale warm front and over central and southern Oklahoma east of a dryline. Figure 1 displays the reported severe weather events occurring between 1200 UTC 13 March and 0600 UTC 14 March 1990 (via the Storm Prediction Center, March 1990). Because the outbreak's most violent and deadliest tornado occurred in Hesston, hereafter this case will be referred to as the Hesston case.

For a conventional discussion of the synoptic and mesoscale characteristics of this event, the reader is referred to Davies et al. (1994). This section examines the nature of the potential vorticity features that were important to the synoptic-scale environment.

Figure 2 displays the evolution of analyzed tropopause potential temperature $\theta_{\mathrm{tr}}$ and winds from 1200 UTC 13 March until 0000 UTC 14 March 1990. These charts were created using vertical interpolation (Morgan and Nielsen-Gammon 1998). On the morning of the tornado outbreak at 1200 UTC 13 March (Fig. 2a), 


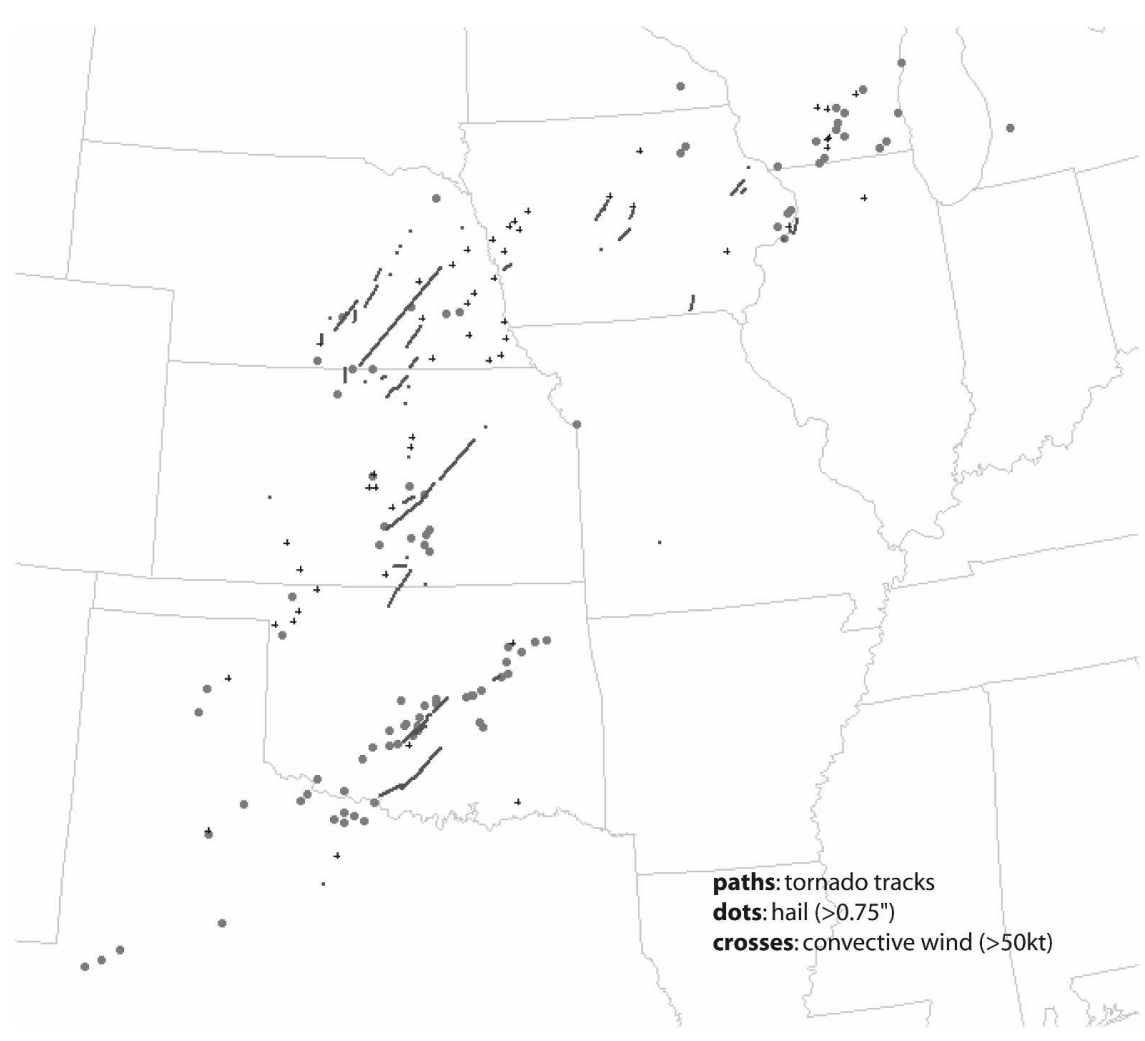

FIG. 1. Severe weather events reported from 1200 UTC 13 Mar to 0600 UTC 14 Mar 1990.

the upper-tropospheric flow pattern is dominated by a large vortex over the western United States centered over eastern Nevada and western Utah, as evinced by the presence of anomalously low $\theta_{\mathrm{tr}}$ and a cyclonic wind pattern on the tropopause. The strong gradient of $\theta_{\mathrm{tr}}$ in the base of this trough represents a steeply sloping tropopause, a structure associated with jet streaks like the one centered near the Baja Peninsula at this time. This particular jet streak is embedded within a band of strong westerly to southwesterly flow extending from Mexico northeastward into the central United States. A weaker tropopause trough (manifested as cyclonic wind curvature and locally lower $\theta_{\mathrm{tr}}$ ) is evident farther east over the lower Mississippi River Valley. On the eastern periphery of the large-scale western U.S. vortex, a minor shortwave trough axis (demarcated with a dashed line) is lifting northeastward toward the high plains. This shortwave trough is embedded within a strong PV gradient. ${ }^{1}$ The trough, manifested as an eastward protrusion of low $\theta_{\mathrm{tr}}$ from the large-scale vortex, is here-

\footnotetext{
${ }^{1}$ Morgan and Nielsen-Gammon (1998) demonstrate that for adiabatic flow, anomalously high PV values on pressure surfaces intersecting the tropopause strongly correlate with anomalously cold potential temperatures on the tropopause.
}

after referred to as the stratospheric protrusion (SP), because it corresponds to an eastward protrusion of stratospheric PV on the $325-335-\mathrm{K}$ isentropic surfaces. By 1800 UTC 13 March the SP has ejected northeastward into the southern high plains and is centered over the Oklahoma-Texas Panhandles (Fig. 2b). Strong southwesterly flow aloft, a pattern often associated with severe thunderstorm outbreaks, persists over the plains throughout the entire period. By 0000 UTC 14 March, the SP has lost some amplitude and continued northeastward in response to strong cold advection on the eastern flank of the large-scale western U.S. trough.

A dynamic tropopause analysis similar to the one performed by Bosart and Lackmann (1995) suggests that the tropopause structure downstream of the largescale western U.S. vortex is important to the establishment of an environment favorable for widespread severe convection. At 1200 UTC March 13 (Fig. 3a), a plume of surface air with $\theta_{e}$ greater than $324 \mathrm{~K}$ exists within a broad swath east and poleward of an extratropical cyclone centered near the western Oklahoma Panhandle. The warm front marking the northeastern edge of this surface plume extends northeast of the surface low to eastern Iowa where it begins to lose definition. The presence of the shortwave trough over 


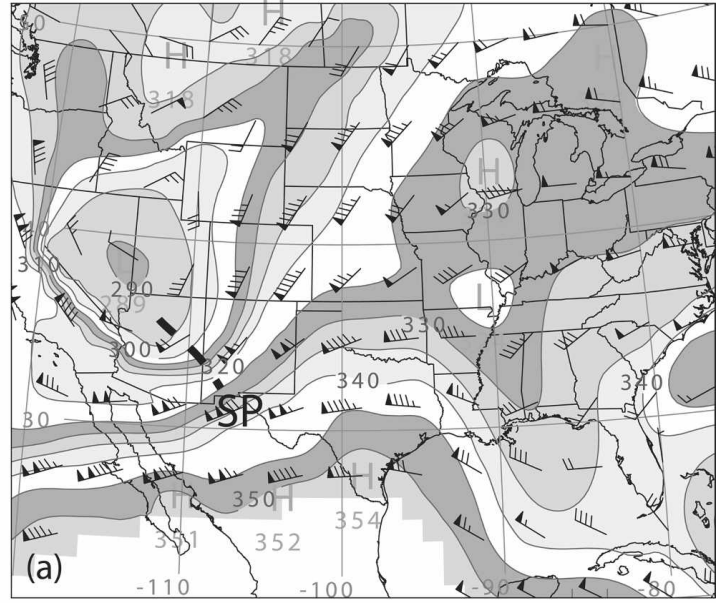

$900313 / 1200$ TROP THTA, V

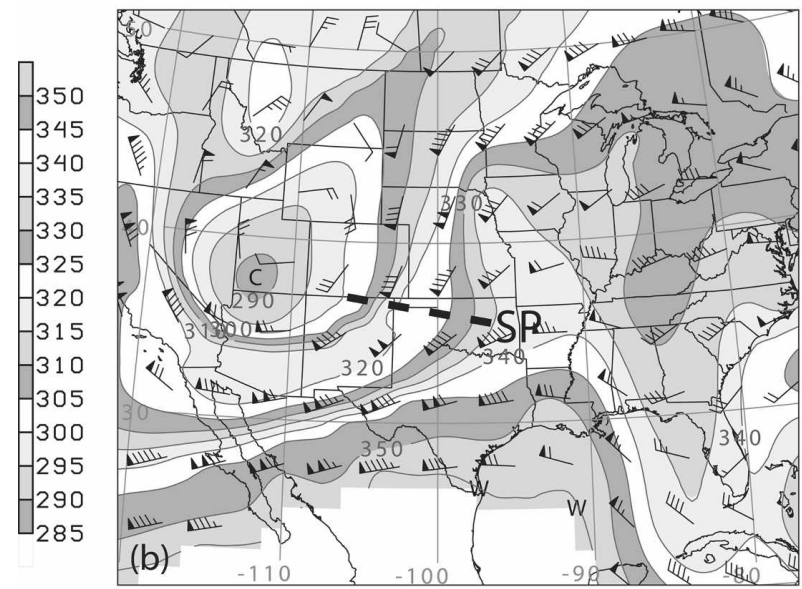

$900313 / 1800$ TROP THTA, V

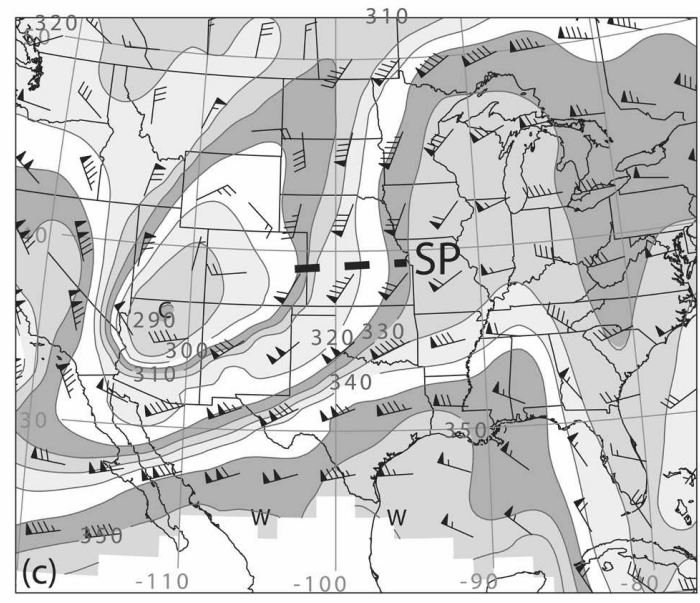

$900314 / 0000$ TROP THTA, V

FIG. 2. Analyzed tropopause (defined as the 1.5-PVU surface) potential temperature (shading; $\mathrm{K}$ ) and winds (barbs; kt) at (a) 1200 UTC 13 Mar, (b) 1800 UTC 13 Mar, and (c) 0000 UTC 14 Mar 1990. The black dashed line segments denote the axis of the SP (see text for an explanation of the SP).

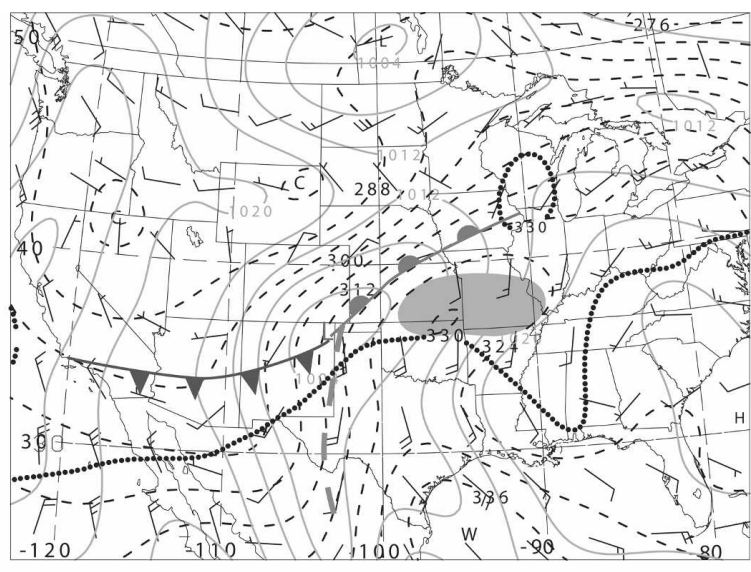

$900313 / 1200$ SFC THTAE,V,MSLP,TROP $330 \mathrm{~K}$

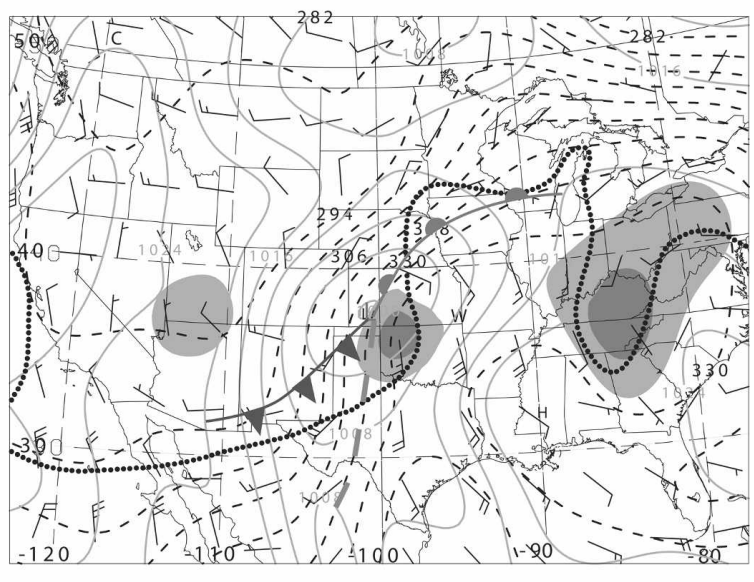

$900313 / 1800$ SFC THTAE, V, MSLP, TROP330K

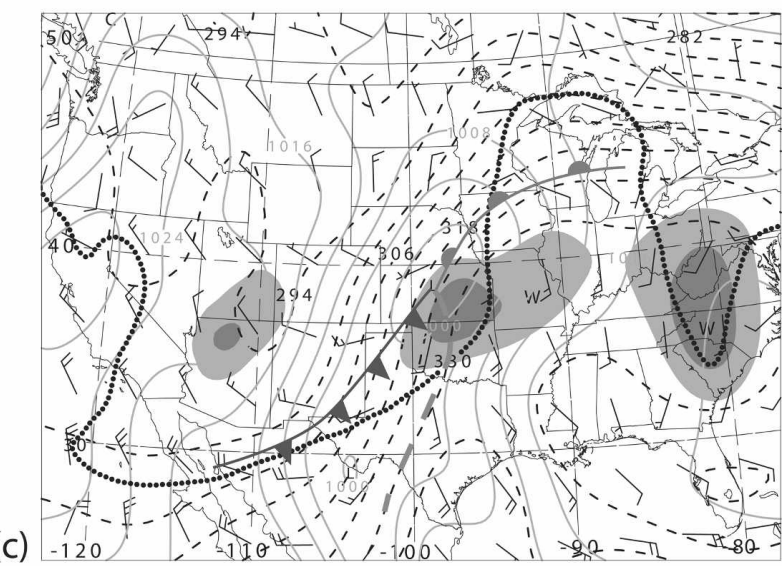

$900314 / 0000$ SFC THTAE, V,MSLP,TROP $330 \mathrm{~K}$

FIG. 3. The analyzed surface $\theta_{e}$ (K; dashed black contours) plotted every $6 \mathrm{~K}$, MSLP (solid gray contours) with an interval of 4 $\mathrm{hPa}$, surface winds (kts), the $330-\mathrm{K}$ isentrope on the dynamic tropopause (thick dotted contour), and the coupling index (light shading for values between 0 and $-4 \mathrm{~K}$; dark shading for values less than -4 K) at (a) 1200 UTC 13 Mar, (b) 1800 UTC 13 Mar, and (c) 0000 UTC 14 Mar 1990. Also drawn are subjectively analyzed front and dryline positions. 
the southeastern United States noted in Fig. 2a results in a tropopause (as demarcated in this instance by the $330-\mathrm{K} \theta_{\text {tr }}$ isentrope, plotted in Fig. 3 as a thick dotted contour) that is displaced significantly equatorward relative to the surface warm front. The northward advance of relatively high surface $\theta_{e}$ beneath potentially cold tropopause air can lead to a conditionally unstable vertical stratification. Such tropospheric deep instability can be diagnosed using the coupling index defined by Bosart and Lackmann (1995). The coupling index, computed as the difference between the potential temperature at the dynamic tropopause and the surface $\theta_{e}$ at each grid point, is negative across much of the warm sector south of the warm front and north of the $330-\mathrm{K}$ tropopause isentrope. A shortwave ridge between the western and southeastern U.S. troughs yields an environment lacking in conditional instability south of this region. In addition to contributing to an unstable environment, the superposition of a steeply sloped tropopause and meridionally amplified warm sector results in an environment possessing strong vertical shear. This can be seen by noting that the region of negative coupling index in Fig. 3a is characterized by strong southeasterly surface winds superposed by strong zonal winds aloft associated with the $\theta_{\text {tr }}$ gradient there (Fig. 2a).

By early afternoon, the SP has reached peak amplitude on the tropopause as it ejects into the southern plains, resulting in the sharp eastward protrusion of the 330-K tropopause isentrope over Oklahoma (Fig. 3b). In fact, by 1800 UTC the $330-\mathrm{K}$ isentrope lies about 200 $\mathrm{km}$ east of the same-valued surface $\theta_{e}$ contour, resulting in a strongly buoyant air mass just southeast of the surface low across western Oklahoma and southwestern Kansas (as evinced by coupling index values below $-4 \mathrm{~K}$ there) where severe thunderstorms erupted $3 \mathrm{~h}$ later. Intense deep-layer vertical shear also exists in this area where southwesterly tropopause-level winds exceeding $90 \mathrm{kts}$ overlay southeasterly surface winds east of the surface cyclone. Moreover, given the fact that the SP is embedded in strong southwesterly shear, one can infer the existence of strong forced ascent over the unstable air mass downshear of the SP from either qualitative quasigeostrophic or the PV-based techniques presented by Hoskins et al. (1985). By 0000 UTC 14 March, with the tornado outbreak well under way, the conditionally unstable and highly sheared regime has expanded eastward with the continued progression of the SP (Fig. 3c), enabling the tornado-producing thunderstorms to propagate eastward and persist.

It is clear from examining Fig. 3 that the severe convective environment established over the southern and central plains this day is dependent to some degree on the details of the tropopause topography. For instance, if the SP were less amplified or altogether absent, the spatial coverage and magnitude of the conditional instability would be reduced because a given isentrope of $\theta_{\mathrm{tr}}$ would not lie so far to the east of its surface $\theta_{e}$ counterpart. To the north of the SP, the high surface $\theta_{e}$ air might not lie so far west because the cyclonic winds associated with the SP would be weaker or absent. South of the SP, CAPE might be increased by this effect. Conversely, if the SP were more intense, resulting in a greater localized eastward displacement of the $\theta_{\mathrm{tr}}$ contours, the atmosphere would become even more buoyant over a larger area. A decrease in $\theta_{\text {tr }}$ would directly decrease the coupling index and, because the upper troposphere would necessarily be colder, increase CAPE. A more amplified disturbance would also be accompanied by increased ascent downshear, possibly leading to more widespread convective coverage rather than isolated, long-lived cells. Less obvious is the impact that changes in the orientation and amplitude of various tropopause undulations would have on the strength and distribution of deep-layer vertical shear.

Moreover, the diagnosis provided by Figs. 2 and 3 cannot quantify the degree to which the convective environment is sensitive to the structure and amplitude of tropopause disturbances. This sensitivity is now explored by perturbing the $\theta_{\mathrm{tr}}$ gradient in realistic ways and computing the concomitant changes in CAPE, shear, and related parameters.

\section{Diagnostic technique}

The diagnostic procedures are fully discussed in Part I. Here the salient points are summarized.

The gridded analyses are obtained from the National Centers for Environmental Prediction-National Center for Atmospheric Research (NCEP-NCAR) reanalysis dataset (Kalnay et al. 1996), and the analyses are interpolated to a $1.25^{\circ}$ latitude-longitude grid with a vertical spacing of $50 \mathrm{hPa}$. Data are extrapolated to any belowground pressure surfaces using a technique that attempts to minimize the imbalance between the belowground PV and the below-ground wind and mass fields, so as not to contaminate the PV inversion above ground.

The PV inversion uses the nonlinear balance equations, following Davis and Emanuel (1991), including the time-dependent equations for vertical motion and irrotational flow. The inversion domain includes almost all of North America. The background PV state is defined to be the analyzed fields, and the artificially imposed PV modifications define the perturbations. The 
PV modification, or surgery, scheme is new and is constrained to both preserve the area-averaged PV and produce new PV fields that might plausibly arise through a rearrangement of the existing PV distribution near the tropopause. The surgery is fully constrained by an amplitude, location, and major and minor axis lengths of the area to be modified.

The inverted mass fields provide balanced virtual temperature profiles. To obtain moisture profiles consistent with the balanced virtual temperature profiles, air parcels are assumed to conserve both virtual potential temperature and mixing ratio as they are imagined to adjust vertically to the balanced state. At $1000 \mathrm{hPa}$, the boundary conditions provide that the analyzed temperature and mixing ratio remain fixed through all inversions. The CAPE computed from the balanced atmosphere was found to agree closely with the actual analyzed CAPE, with departures (generally less than $100 \mathrm{~J} \mathrm{~kg}^{-1}$ ) associated with jet streaks and other areas of rapidly varying ageostrophic flow. The balanced CAPE will simply be referred to as CAPE hereafter.

The vertical shear parameters considered below are sensitive to low-level wind profiles, which in turn are strongly affected by surface friction and other unbalanced processes. Rather than estimate the shear parameters from the balanced wind, the full analyzed wind fields are used. The perturbations to the full wind fields are approximated as the difference between the balanced wind field and the modified balanced wind field under PV surgery. Surface winds are used in lieu of mean planetary boundary layer winds for computing the $0-6-\mathrm{km}$ shear parameter.

\section{The first upper-level PV surgery: Amplification of the SP}

\section{a. The altered tropopause}

As discussed in section 2, the SP is proximate to the geographical region soon to experience widespread significant severe weather and is thus a candidate for modification. By so doing, one can readily explore the sensitivity of the severe convective regime to any changes made to the magnitude or shape of this feature. The first experiment in altering the upper-level PV is to amplify the SP at a time just prior to convective initiation (1800 UTC 13 March 1990) by modifying the analyzed PV distribution using the PV modification procedure presented in Part I with the following characteristics: amplitude exponent $A=0.6$; location of maximum perturbation $\left(x_{0}, y_{0}\right)=\left(36.25^{\circ} \mathrm{N}, 100^{\circ} \mathrm{W}\right)$; and anomaly (major, minor) axis lengths $=(4,4)$. Thus, the SP is magnified through the addition of a circular patch of PV with "moderate" amplitude, a modification hereafter referred to as AMP. The amplification is designed to mimic a typical 6-12-h underestimate of the intensity of a short-wave trough ejecting from the intermountain region. The resulting modified $\theta_{\mathrm{tr}}$ distribution (overlaid on the unperturbed $\theta_{\mathrm{tr}}$ ) is displayed in Fig. 4a and the perturbation $\delta \theta_{\text {tr }}$ resulting from the alteration is shown in Fig. 4b. It should be noted that as in Fig. 2, this tropopause map is constructed by vertical interpolation of the modified PV distribution to the 1.5-potential vorticity units (PVU) surface.

In terms of quantities more familiar to operational meteorologists, an amplified SP is associated with lowered 500-hPa balanced geopotential heights (Fig. 5a) and a southeastward protrusion of positive balanced relative vorticity (Fig. 5b) into western Oklahoma. It is notable that the SP amplification represents a rather small perturbation to the total analyzed midtropospheric flow.

\section{$b$. The effect of amplifying the SP on CAPE and convective inhibition (CIN)}

Amplifying the SP increases the CAPE over the region soon to be experiencing convective initiation. There is a westward displacement (beneath the region in which the upper-level PV is most strongly increased) of CAPE contours on the western periphery of the large CAPE "pool" (Fig. 6a) centered over eastern Kansas and western Missouri. The western region of large CAPE corresponds to the area of negative coupling index in Fig. 3b. An increase in CAPE beneath an intensified SP is consistent with the concomitant reduction of balanced temperature throughout a deep tropospheric column at grid points beneath the SP (Fig. 6b) and with the reduction in $\theta_{\mathrm{tr}}$ noted in Fig. $4 \mathrm{~b}$.

A comparison of balanced soundings at a single grid point within the warm sector beneath the region of greatest SP amplification reveals that a stronger uppertropospheric PV anomaly is associated with a cooler and moister mid- and upper troposphere (Fig. 6b; see also Part I). For a parcel with fixed surface characteristics, this yields increased CAPE for the perturbed balanced state. The region experiencing a nonnegligible increase in CAPE is confined to a subsynoptic area centered over northwestern Oklahoma, with a maximum increase of $355 \mathrm{~J} \mathrm{~kg}^{-1}$ (Fig. 7a).

This increase in CAPE, centered near the western gradient of the CAPE distribution, represents a change of between $20 \%$ and $30 \%$ (refer back to Fig. 6 a). The implication is that if the SP were more intense than analyzed, surface-based parcels in the storm initiation region (i.e., near the western edge of the CAPE pool) would be significantly more unstable for upright convection. 


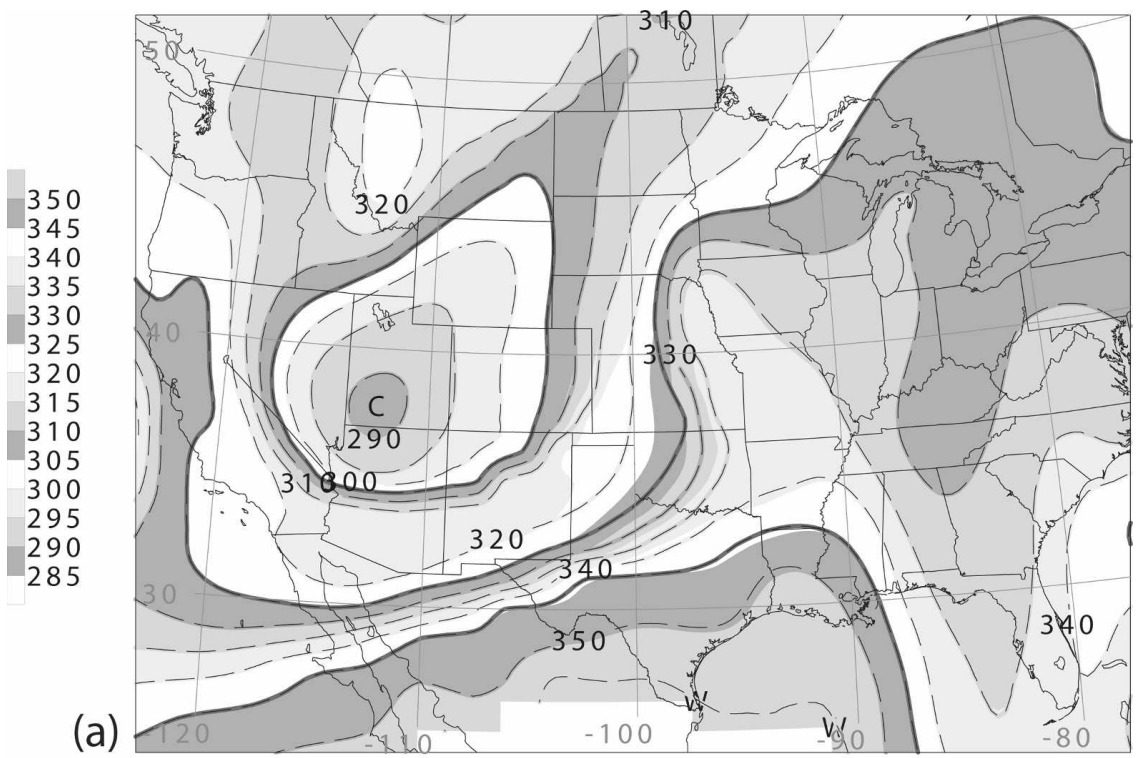

$900313 / 1800$ ORIG, MODIFIED TROP THTA

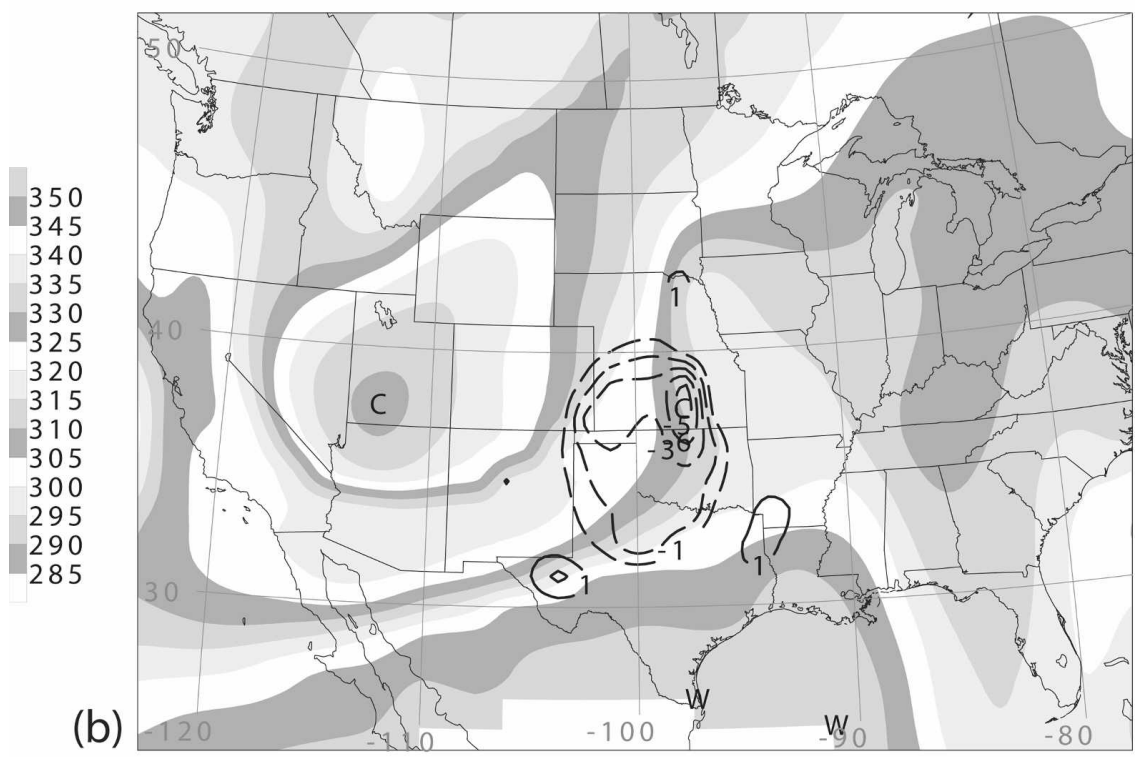

$900313 / 1800$ ORIG, MOD - ORIG TROP THTA

FIG. 4. (a) Analyzed (shading) and modified (dashed contours) $\theta_{\mathrm{tr}}(\mathrm{K})$ for the case where the shortwave trough centered near western Oklahoma at 1800 UTC 13 Mar is amplified. (b) Analyzed (shading) $\theta_{\mathrm{tr}}$ and the difference between modified and analyzed fields plotted (contours, dashed negative; plotted every $1 \mathrm{~K}$ ).

Unlike the CAPE perturbation, which is maximized beneath the amplified SP, decreases in CIN occur only along the northern and southern flanks of the CAPE anomaly. The CIN is most sensitive to lower- and midtropospheric temperature changes at locations where the negative buoyancy is vertically distributed through a relatively deep layer. Over the most destabilized region, CIN is largely confined to a relatively shallow inversion layer and is therefore not sensitive to small temperature changes within the inversion. The CIN changes are driven by decreases of the lower-tropospheric temperature (Fig. 7b). A north-south elongation of the midtropospheric cold anomaly coincides with the greatest reductions of CIN on the periphery of the destabilized region.

The meridional distortion of the thermal anomaly 


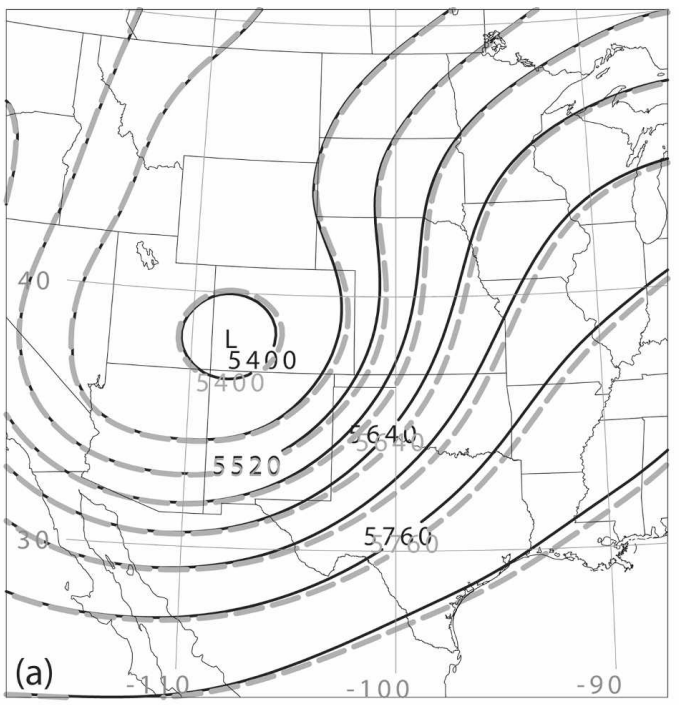

$900313 / 1800500$ MB ORIG (black), AMP (gray) BALZ

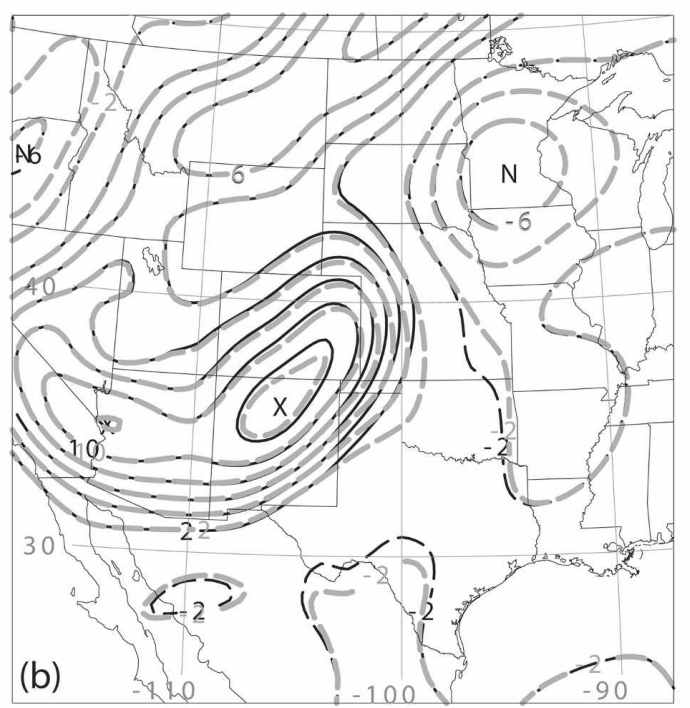

$900313 / 1800500$ MB ORIG (black), AMP (gray) VOR

FIG. 5. (a) Original (solid) and modified (dashed) balanced 500hPa heights associated with the amplified SP at 1800 UTC 13 Mar 1990. (b) Original (solid) and modified (dashed) 500-hPa balanced relative vorticity $\zeta$ (plotted every $2 \mathrm{~s}^{-1}$ ) associated with AMP at the same time as in (a).

into regions far removed from the SP anomaly is a farfield response produced by the existence of the background tropopause PV gradient, explained in Part II in terms of the Thorpe and Bishop (1995) electrostatics analogy.

An intensified SP would also produce changes in the vertical motion field that are diagnosable using the nonlinear balance equation set (Part I). In this case, AMP changes the $700-\mathrm{hPa}$ vertical motion by roughly 0.5 $\mathrm{cm} \mathrm{s}^{-1}$ (Fig. $7 \mathrm{~b}$ ), representing a $5 \%-10 \%$ change to the
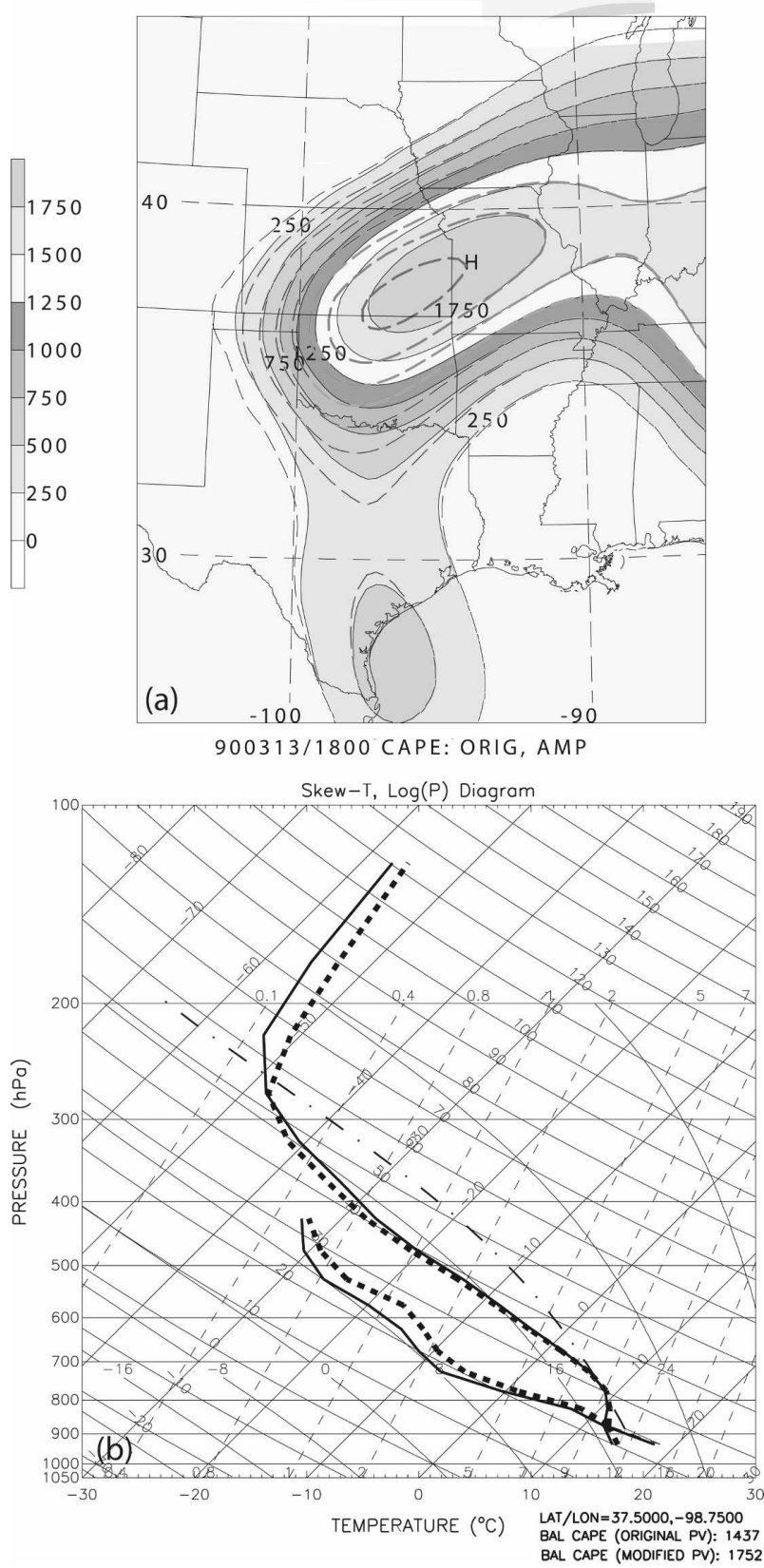

FIG. 6. (a) CAPE associated with the original (shading) and AMP PV (dashed). (b) Soundings associated with unperturbed (solid) and AMP (dashed) PV distribution with the parcel pseudoadiabatic ascent curve shown.

total vertical velocity field (not shown). A change in vertical motion this small is not likely to drastically change the spatial coverage of convective cells. Consistent with the Trenberth approximation for the forcing of vertical motion (Trenberth 1978), the vertical motion perturbation dipole is oriented along the deep-layer shear vector with ascent (descent) downshear (upshear) of the SP. 


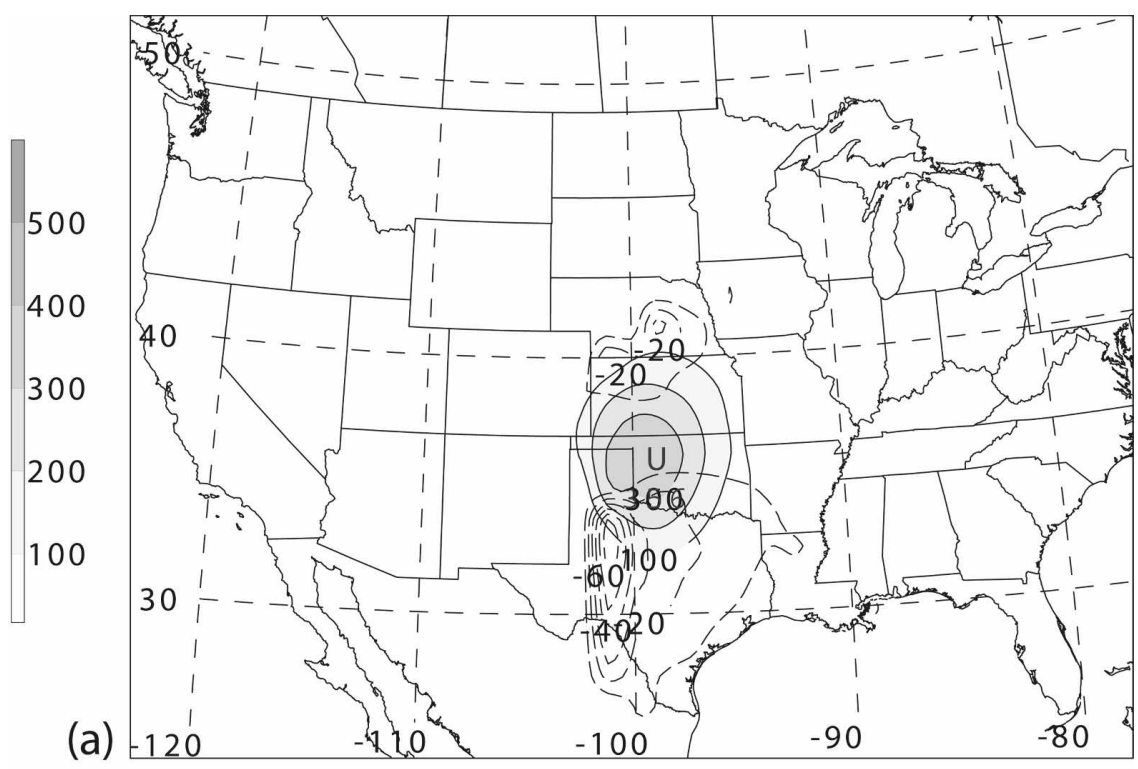

900313/1800 BAL CAPE PERT (fill), CIN PERT (contour)

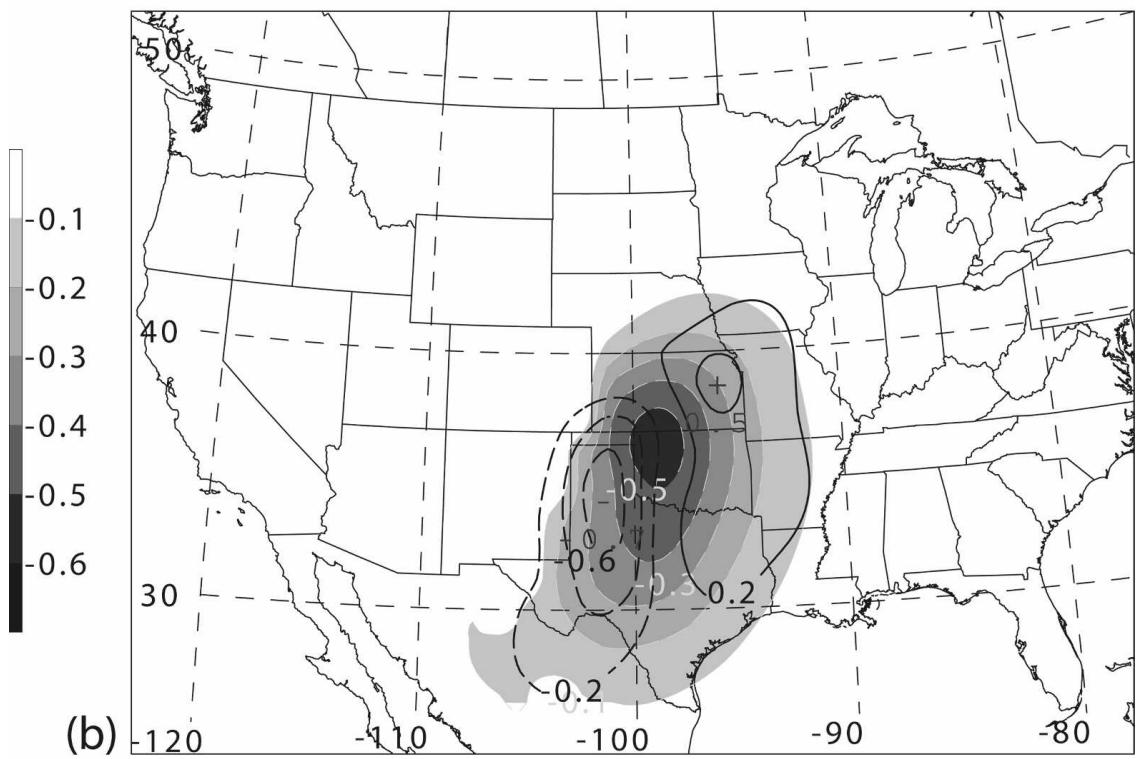

900313/1800 BAL TEMP PERT (fill), W PERT (contour)

FIG. 7. (a) CAPE (shading) and CIN (contours) perturbations produced by AMP and (b) the balanced temperature perturbation at $724 \mathrm{hPa}$ (shading; positive values suppressed) and vertical motion perturbation at $700 \mathrm{hPa}$ (contours) at 1800 UTC $13 \mathrm{Mar}$.

An altered upper-tropospheric trough configuration affects not only the instantaneous balanced flow, but also the advections of PV and surface $\theta_{e}$ by that flow. The diagnosis presented above explicitly considers only the instantaneous changes associated with the new balanced state, but the evolution of that state will also lead to changes in CAPE and CIN over time. Considering the effect of surface $\theta_{e}$ advection on the tendency of
CAPE (not shown), horizontal transports of $\theta_{e}$ increase CAPE significantly only along the warm front where the surface $\theta_{e}$ gradient is large and advection can be substantial. Even there, the horizontal transport is only modified by at most $0.5 \mathrm{~K}(6 \mathrm{~h})^{-1}$ by the PV modification, which is only $6 \%$ of the total advection. Within the area experiencing the strong instantaneous CAPE increases explicitly tied to SP amplification, modified 
surface $\theta_{e}$ advection is much smaller and has little effect.

\section{c. The effect of amplifying the SP on vertical shear parameters}

The 0-6-km vertical shear and the storm-relative environmental helicity (SREH) are useful for distinguishing between environments supporting tornadic and nonsevere thunderstorms (Davies and Johns 1993; Rasmussen and Blanchard 1998; Craven et al. 2002). The SREH depends on both the vertical shear and the estimated storm motion vector (SMV; computed following Bunkers et al. 2000). For more details, see Part I.

Assessment of the effect of PV changes on these shear parameters involves analysis of both the change in vertical shear and the effect of that change in the context of the preexisting vector shear profile.

The amplified SP is a positive upper-tropospheric PV anomaly and is therefore associated with a downwarddecaying negative balanced streamfunction anomaly (Thorpe 1986, his Fig. 1), $\Psi^{\prime}$. Consequently, the horizontal gradient of $\Psi^{\prime}$ also decays downward, resulting in a cyclonic perturbation vector wind field that is vertically sheared beneath the flanks of the SP. The cyclonic pattern of perturbation $0-6-\mathrm{km}$ shear vectors displayed in Fig. 8a opposes the southwesterly background shear vectors over a region from southwestern Nebraska to northeastern New Mexico. The westsouthwesterly perturbation shear vectors to the southeast of the SP slightly augment the background shear over southern portions of the outbreak region (southwestern Oklahoma and northern Texas). Thus, the change in shear magnitude (the gray contoured field in Fig. $8 \mathrm{~b}$ ) is negative primarily northwest of the region with positive CAPE and positive (but small) over the southern portions of the unstable region. These results demonstrate that amplifying the SP has a negligible impact on deep-layer shear over the convective outbreak region. The effect on $0-3-\mathrm{km}$ storm-relative helicity (Davies-Jones 1984), however, is nonnegligible over the northern portion of the geographical area that will soon experience the tornado outbreak, with SREH values reduced over much of this region and increased along and behind the Texas dryline (Fig. 8b). As is the case with the deep-layer shear, SREH is nearly unaffected to the southeast of the amplified SP over Texas and southern Oklahoma.

A notable asymmetry exists in the perturbation shear magnitude: the negative values northwest of the PV modification are roughly 2.5 times stronger than the positive values southeast of the modification. In Part II it was shown that the change in the background "di-

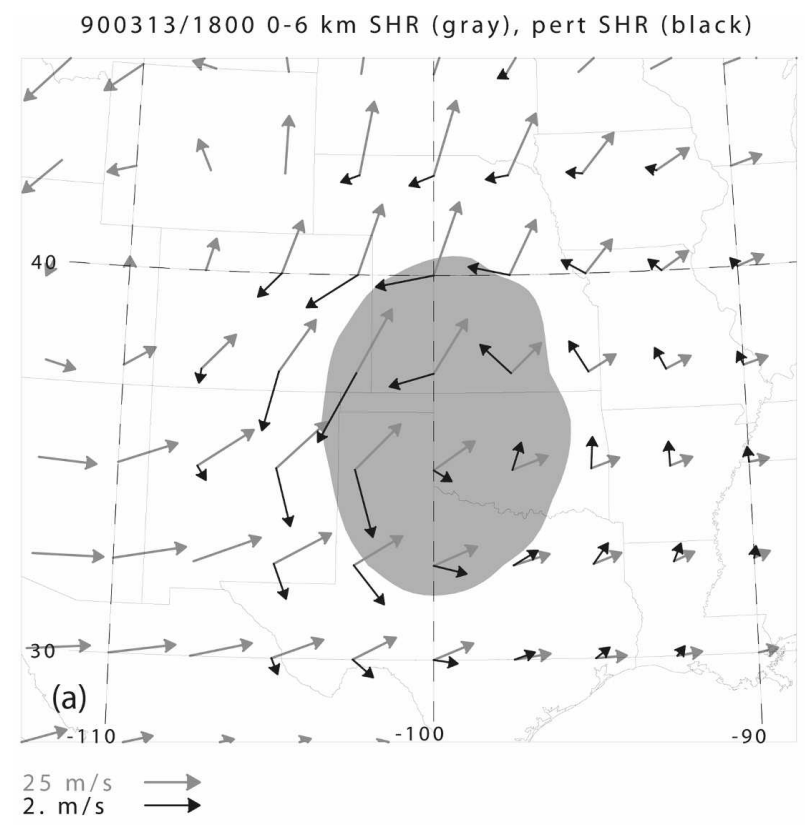

$900313 / 1800$ pert SHR MAG (gray), pert SREH (black)

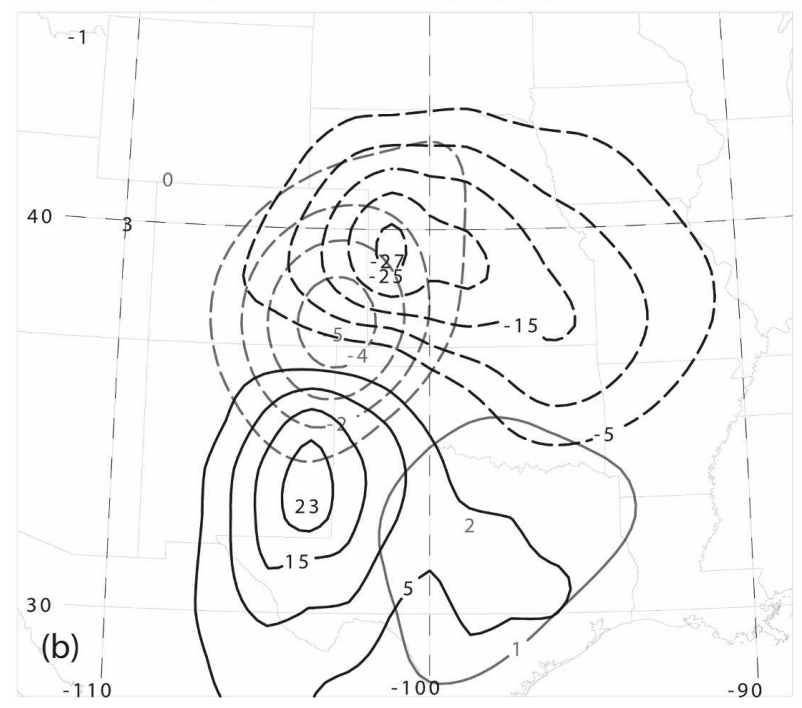

Fig. 8. (a) Analyzed (gray arrows) and perturbation (black) 0-6-km shear vectors; the cold tropopause anomaly associated with AMP is also displayed (shading, values less than or equal to $-1 \mathrm{~K}$ ) to show the spatial relationship between the PV anomaly and the perturbation shear vectors and (b) anomalies of 0-6-km shear (gray) and 0-3-km SREH anomalies (black) at 1800 UTC 13 Mar. Note that the vectors are drawn to different scales, shown in the legend beneath (a).

electric" across the jet contributes to faster horizontal decay of $\Psi^{\prime}$ on the anomaly's western flank, resulting in a stronger horizontal gradient there, and thus a stronger wind response.

The impact of AMP on the wind profile is further illustrated by comparing hodographs associated with 
HODOGRAPH: ANALYZED VS. ANALYZED+DVBAL

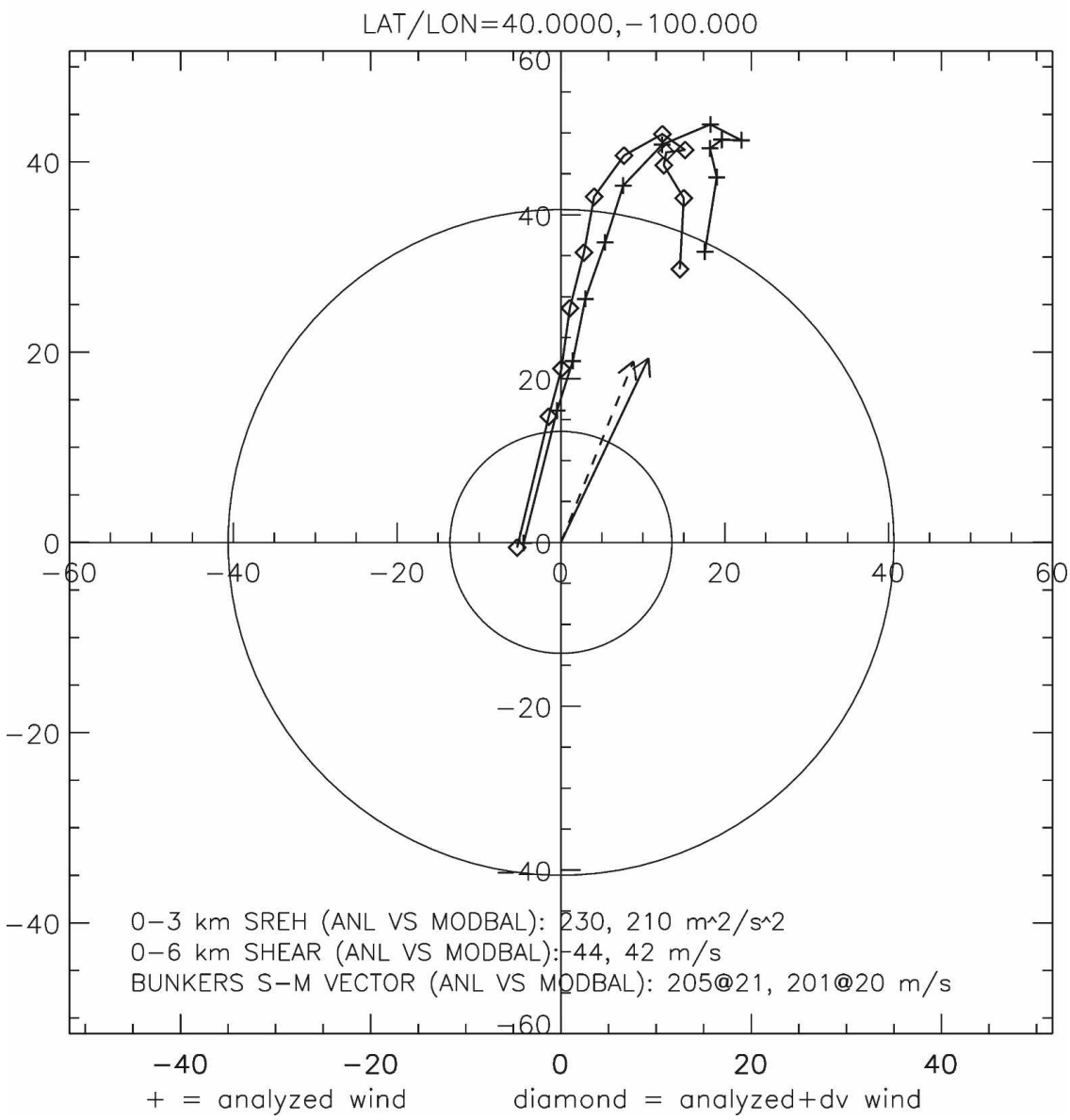

FIG. 9. Hodographs for the analyzed and modified winds at 1800 UTC 13 Mar 1990 at $40^{\circ} \mathrm{N}$, $100^{\circ} \mathrm{W}$ for the amplified SP case. The dashed vector is the Bunkers SMV associated with the modified flow. The shear parameter values, as well as the SMV magnitude and direction, are listed below the diagram for both original and modified balanced hodographs.

the analyzed and modified wind profiles. ${ }^{2}$ Hodographs sampled from a grid point near the largest decrease in SREH are particularly revealing (Fig. 9).

The grid point chosen is one immediately northeast of the surface cyclone and close to the location where one of the most significant tornadic storms of the day forms. It is clear that amplifying the SP induces the greatest changes to the winds aloft, with decreasing impact at lower altitudes. The SMV associated with the modified balanced winds has backed very slightly (from $205^{\circ}$ to $201^{\circ}$ ) with almost no change in magnitude (21 to $20 \mathrm{~m} \mathrm{~s}^{-1}$ ), while the $0-6-\mathrm{km}$ shear magnitude and

\footnotetext{
${ }^{2}$ As described in Part I, the modified wind profile is obtained by adding to the analyzed wind the balanced perturbation wind field, which in turn is found by inverting the PV modification (the amplified SP in this case) and taking horizontal derivatives of $\Psi^{\prime}$.
}

SREH have decreased from 44 to $42 \mathrm{~m} \mathrm{~s}^{-1}$ and 230 to $210 \mathrm{~m}^{2} \mathrm{~s}^{-2}$, respectively.

The SREH is a function of both the SMV and the vertical variation of wind over the lower troposphere, usually chosen to be the lowest $3 \mathrm{~km}$. Changes in SREH can be attributed to one effect or a combination of two effects: changes to the SMV and/or to the $0-3-\mathrm{km}$ wind profile itself. If the SMV under AMP had not changed, SREH would have increased to $248 \mathrm{~m}^{2} \mathrm{~s}^{-2}$. This contrasts with the $20 \mathrm{~m}^{2} \mathrm{~s}^{-2}$ decrease noted in Fig. 9, so the slight backing and weakening of the SMV, rather than the weak changes in the shear profile, are primarily responsible for the diagnosed decrease in SREH. This result might have been anticipated from the fact that the Bunkers et al. (2000) SMV is based, in part, on the winds averaged over the lowest $6 \mathrm{~km}$, and is thus affected more by upper-level PV alterations than are the lower-tropospheric winds. 
Beyond reducing the SREH, leftward rotation of the SMV can affect the convective mode by changing the manner in which neighboring convective cells interact. Bluestein and Weisman (2000) find that a broken line of neighboring supercells is most favored when the deep-layer shear vector is oblique to the initiating boundary, with squall lines forming in cases where the shear vector is either parallel to or perpendicular to the boundary (with isolated supercells at either end of the line in the latter case and on the downshear end of the line in the former). In this case, amplifying the SP causes storm motions to deviate only slightly to the left so changes in shear vector-boundary orientation would generally be negligible. Surface boundary orientations might also be modified by the time-integrated effects of upper-level PV differences in the real atmosphere though.

\section{The second upper-level PV surgery: Removal of the SP}

\section{a. Changes in the PV distribution}

A second experiment is conducted to investigate the impact on the convective parameter space of virtually eliminating the SP altogether. Removing the SP is accomplished by reducing the PV by an amplitude factor $A=-0.4$, a modification tantamount to imposing a negatively signed PV anomaly at the same location and using the same geometric characteristics as the preceding amplification experiment (Fig. 10).

The SP removal (hereafter referred to as the NOPV case) is manifest on the tropopause as a sharp westward displacement of $\theta_{\mathrm{tr}}$ contours (Fig. 10a). For example, the unperturbed position of the $325-\mathrm{K}$ tropopause isentrope meanders from central Nebraska southwestward to the Texas Panhandle with a pronounced convexity over western Oklahoma. After SP removal, the 325-K isentrope is pushed westward and even reverses curvature over the southern high plains. The net effect is to introduce a substantial warm anomaly on the tropopause centered near the Oklahoma-Kansas border (Fig. 10b) while repositioning the $\theta_{\text {tr }}$ gradient westward. This repositioning is in contrast to the result of amplifying the SP, which caused an in situ strengthening of the $\theta_{\mathrm{tr}}$ gradient with no reorientation of the contours and gradient.

\section{b. The impact of SP removal on the convective parameters}

Removing the SP produces responses in the CAPE, CIN, and vertical motion fields that are oppositely signed but spatially similar to the changes associated with amplifying the SP. The CAPE is reduced by as much as $359 \mathrm{~J} \mathrm{~kg}^{-1}$ beneath the weakened SP, while $\mathrm{CIN}$ is increased along the Texas dryline and just north of the warm front (Fig. 11a). As was the case for AMP, the vertical motion perturbation is dipolar with weakly enhanced descent (ascent) forced downshear (upshear) of the mitigated SP (Fig. 11b).

The most notable difference in the response fields between AMP and NOPV is that the lower- to midtropospheric thermal anomaly is considerably weaker in the latter case (Fig. 11b). The difference is because the Rossby penetration depth is reduced in NOPV owing to the increased tropospheric static stability beneath the negative PV anomaly produced by SP removal.

The shear and SREH perturbations produced by NOPV are also opposite in sign but nearly identical in spatial distribution to those produced by AMP (Fig. 12). The $15-20 \mathrm{~m}^{2} \mathrm{~s}^{-2}$ increase in SREH over northwest Kansas and southwestern Nebraska is associated with a clockwise rotation of the deep-layer shear vector and the attendant rightward rotation of the SMV as shown in Fig. 12a. As in the AMP experiment, this represents an average SREH increase of only about $5 \%$ to $10 \%$.

\section{The influence of PV changes on the convective parameter space}

The Rasmussen and Blanchard (1998, hereafter RB98) climatology is now used to choose specific "threshold" values of the convective parameters. The idea is to determine whether and to what extent PV modifications influence the "movement" of these thresholds relative to the locations where intense moist convection is observed to initiate. Two of the parameters being considered here, CAPE and SREH, are shown by RB98 to have considerable ability to discriminate between the extremes of the storm classification spectrum, primarily through their ability to distinguish between supercellular and nonsupercellular convection. For example, the results of RB98 reveal that less than $25 \%$ of soundings associated with significant tornadoes (defined to be those that produce F2 or greater damage) have CAPE $<519 \mathrm{~J} \mathrm{~kg}^{-1}$. Thus, one might plot the $519 \mathrm{~J} \mathrm{~kg}^{-1}$ balanced and modified balanced CAPE contours (for all PV modifications under consideration) at a time just prior to convective initiation and compare their positions in relation to the locations where convection subsequently develops. A large relative contour displacement (i.e., relative to locations where the tornadic storms form) is interpreted to indicate that a given PV alteration will make tornadic supercells more or less likely. Given differences between the way RB98 and the current study compute CAPE (RB98 calculate CAPE based on a parcel rep- 


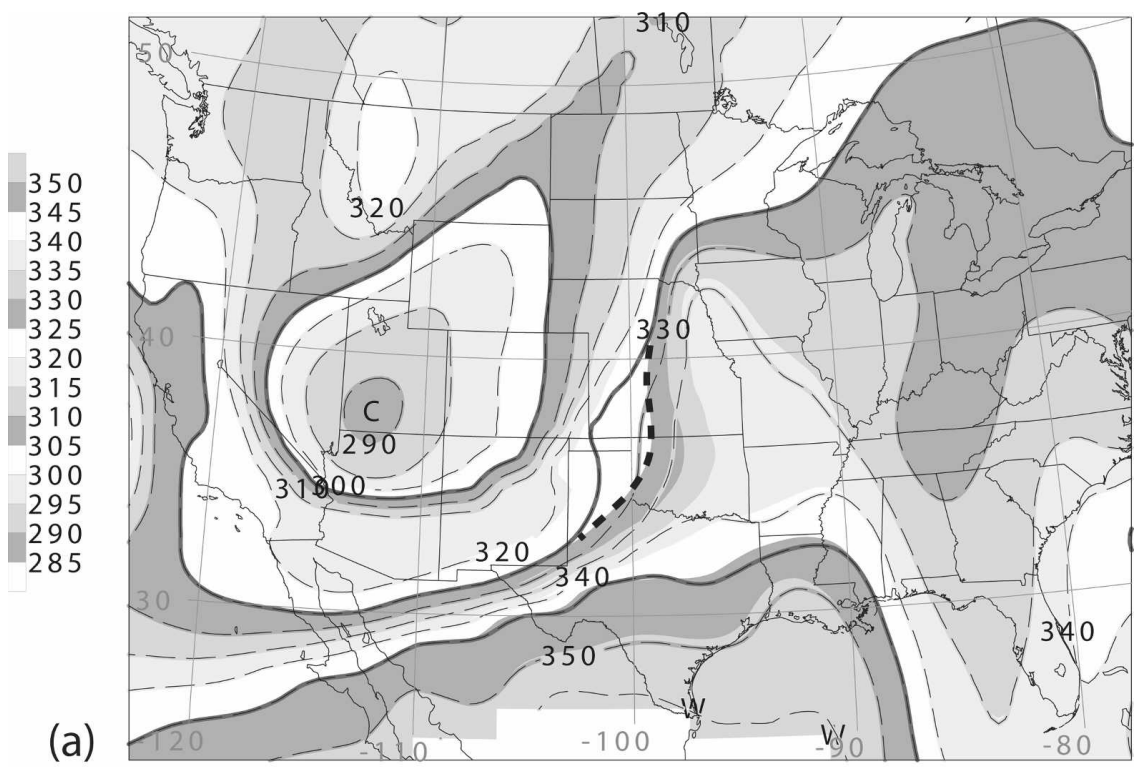

$900313 / 1800$ ORIG, MODIFIED TROP THTA

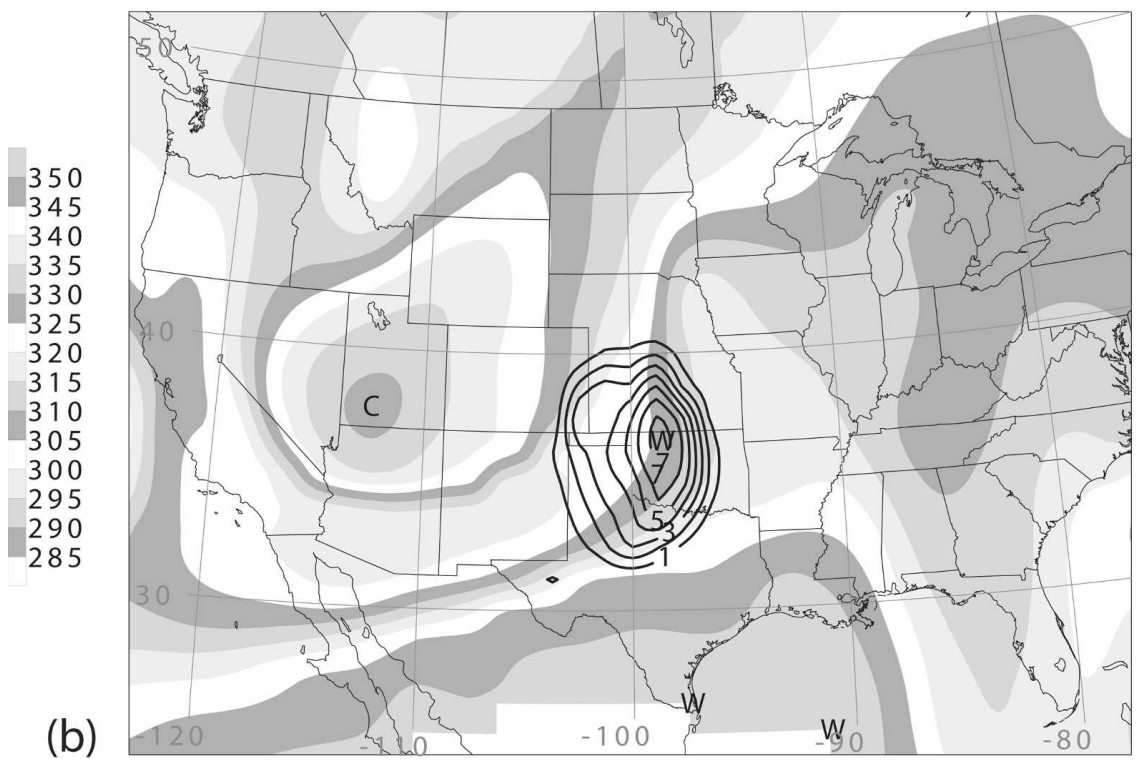

$900313 / 1800$ ORIG, MOD - ORIG TROP THTA

FIG. 10. As in Fig. 4, but for the NOPV experiment. The unperturbed position of the $325-\mathrm{K}$ tropopause isentrope within the SP is highlighted by the dashed curve in (a).

resenting average $\theta_{v}$ in the lowest $100 \mathrm{hPa}$, often denoted MLCAPE for mean-layer CAPE, whereas CAPE here is based on a surface parcel), the CAPE = $500 \mathrm{~J} \mathrm{~kg}^{-1}$ contour is the threshold chosen for that parameter. The results of RB98 suggest choosing a threshold value of SREH equal to $168 \mathrm{~m}^{2} \mathrm{~s}^{-2}$ because such a value seems to cleanly separate regimes clearly supportive of tornadic supercell convection from those that might also support nonsupercell convection.
It should be noted that several empirical studies (Craven et al. 2002; Thompson et al. 2003; Rasmussen 2003) subsequent to RB98 have demonstrated that a refined set of parameters (specifically, MLCAPE, lifted condensation level height, and 0-1-km SREH) do an even better job at discriminating between nontornadic and tornadic environments. The current study uses the RB98 parameter space primarily because of the limited vertical resolution of the balanced diagnosis output 

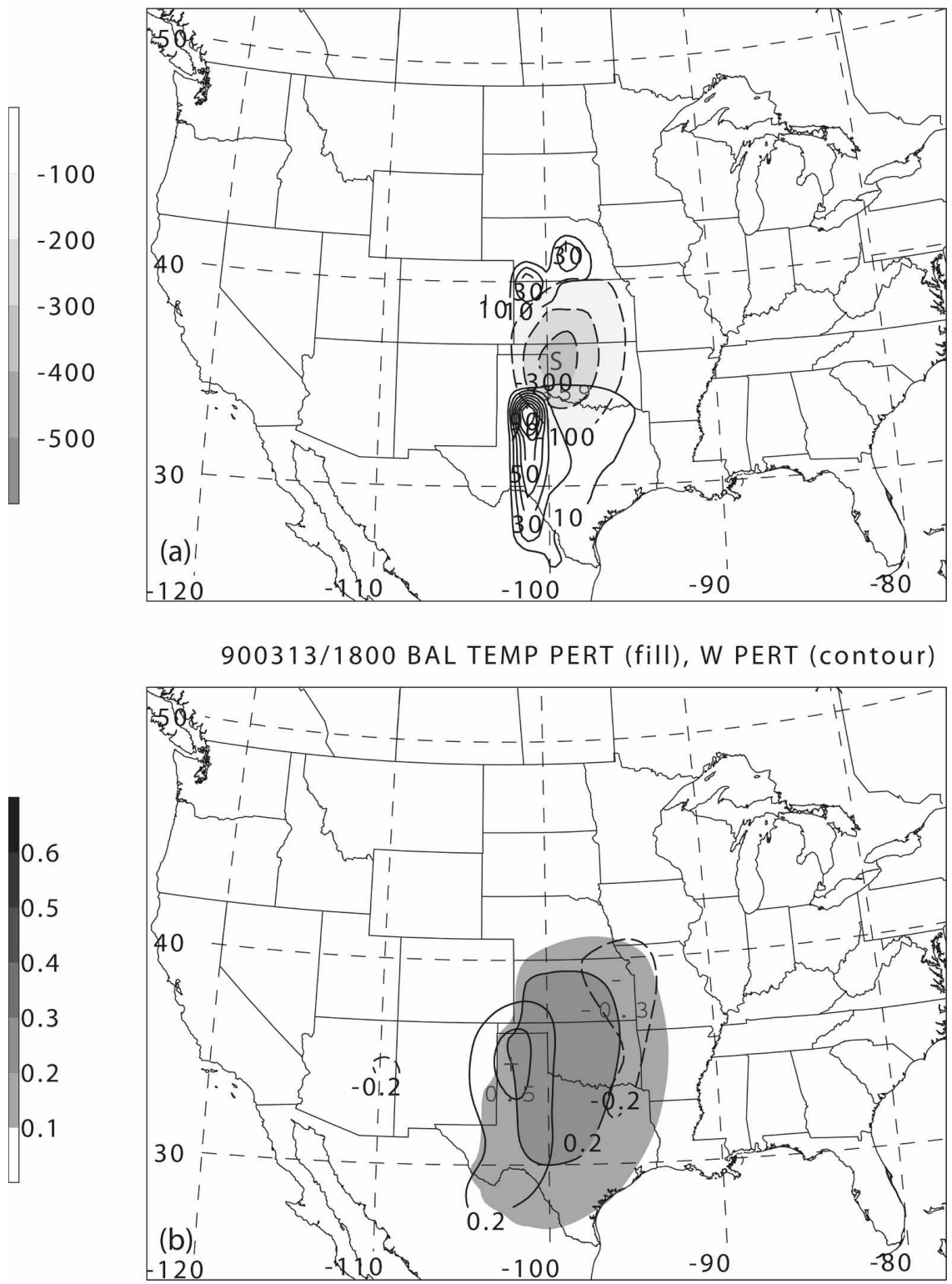

900313/1800 BAL CAPE PERT (fill), CIN PERT (contour)

FIG. 11. As in Fig. 7, but for NOPV.

grid, which results in few vertical gridpoint values available for the computation of the vertically averaged quantities, and also because the effect of PV modifications on winds within the lowest $1 \mathrm{~km}$ is difficult to estimate in the context of friction and topography.

Several so-called "composite" parameters (i.e., those combining CAPE and some vertical shear metric) were found by RB98 to discriminate among the storm classes more strongly than any of the individual parameters. Of the composite parameters considered by RB98, the EHI, defined as

$$
\mathrm{EHI}=\frac{(\mathrm{CAPE}) \times(\mathrm{SREH})}{1.6 \times 10^{5}},
$$

was found to be superior at discriminating among all three storm categories and is therefore the one composite parameter examined in this study. Because those RB98 proximity soundings for which EHI is greater than or equal to 0.77 are found to account for less than $10 \%$ of ordinary cases and greater than $67 \%$ of tornadic cases, this is the EHI threshold value chosen here. The 


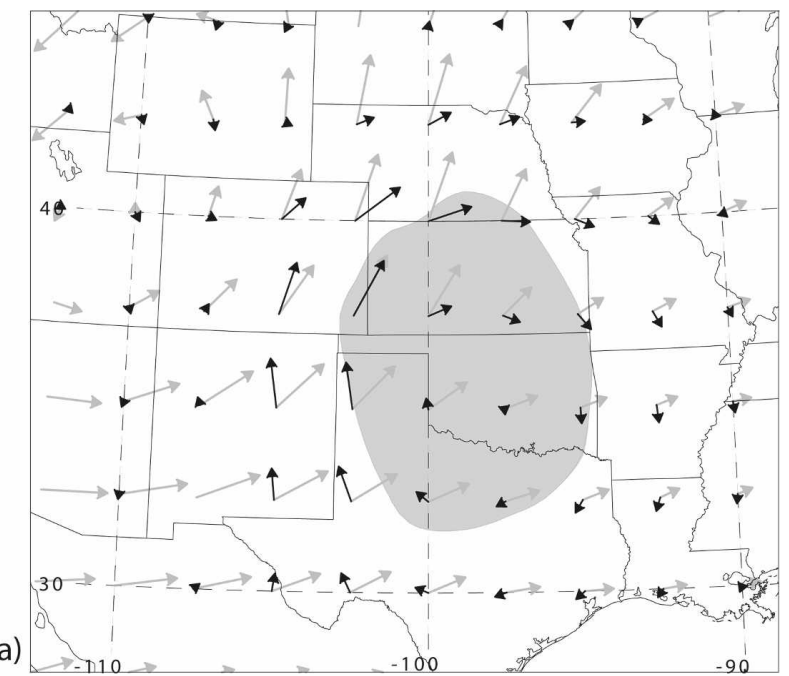

900313/1800 0-6 km SHR (gray), pert SHR (black) 5. kts $\longrightarrow$

(b)

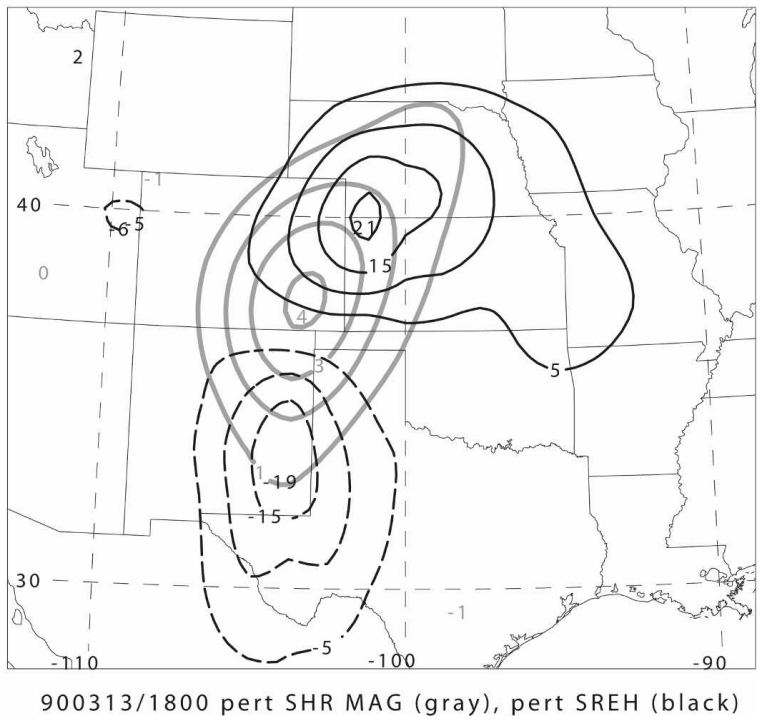

FIG. 12. As in Fig. 8, but for NOPV.

method for comparing the threshold contours just defined is as follows:

1) For each convective parameter considered, the contour corresponding to the threshold analyzed value of that parameter is plotted on a map of the outbreak region. ${ }^{3}$

2) Then the threshold value diagnosed for a specific $P V$ modification is contoured on the same map as the analyzed threshold value plotted in step 1 .

3) The tornado tracks are overplotted on the maps to illustrate how far a given threshold contour moves

${ }^{3}$ Except CAPE, for which the balanced value is used. relative to the beginning points of the tornado tracks. Steps 1 and 2 are repeated for each PV modification (i.e., in this case, once for AMP and again for NOPV).

This procedure results in a series of maps (here called "threshold contour maps") illustrating the spatial displacement of the threshold contours induced by the upper-level PV modifications relative to the tornado tracks.

Threshold contour maps for CAPE, SREH, and EHI are shown in Fig. 13. For each parameter, the threshold contours corresponding to AMP (dashed contours) and NOPV (solid contours) are plotted on the same map background. In each panel except Fig. 13a (for which the balanced CAPE is displayed, as mentioned above), the analyzed threshold contour is plotted to facilitate comparison to the contours associated with both perturbed balanced states (AMP and NOPV).

For all parameters and both upper-level PV modifications (AMP and NOPV), the threshold contour displacement is relatively small compared with the width of the region enclosed by the CAPE, SREH, and EHI curves. With the exception of the Nebraska tornado tracks, all other tornadoes eventually develop within the region enclosed by the CAPE threshold contour, suggesting that SP removal (NOPV) is not sufficient to reduce CAPE below a level likely to be detrimental to tornado formation, especially over the central and southern portion of the outbreak region. Over southeastern Nebraska, most of the tornado tracks (including the 131-mile-long path of the F4 tornado that hit Lawrence, Nebraska) are located outside both the balanced and modified CAPE threshold contour along the warm front, a consequence of the inability of the reanalysis data to properly resolve the position of the warm front.

The SREH plot (Fig. 13b) indicates that the warm front region is characterized by large SREH, a regime that neither PV modification is sufficient to change appreciably. Farther south over central Kansas, the Hesston tornado family initiates near the analyzed SREH threshold contour, thus making this region more susceptible to small changes in its position. The NOPV modification results in a southward expansion of the high SREH environment present over the northern portion of the convective region and amplifying the SP results in a northward retreat of the SREH threshold contour. The southern portion of the convective region (northern Oklahoma to southwestern Oklahoma) is characterized by relatively low SREH in the analyzed state, a regime that is not affected by either upper-level PV alteration. 


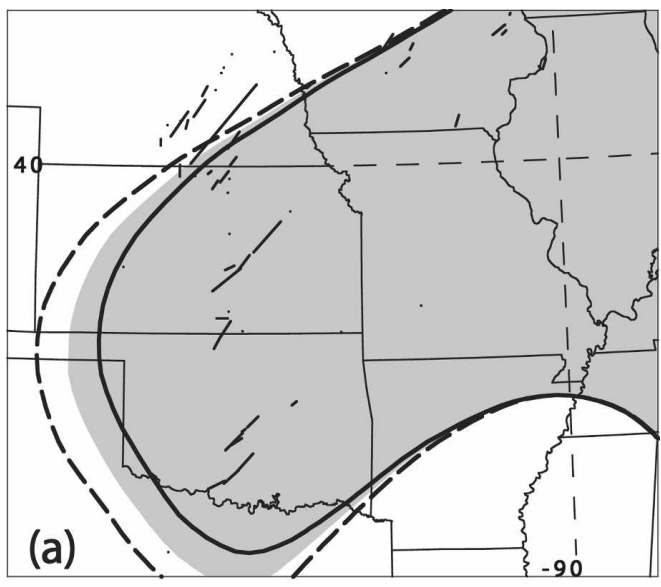

$900313 / 1800$ CAPE TC

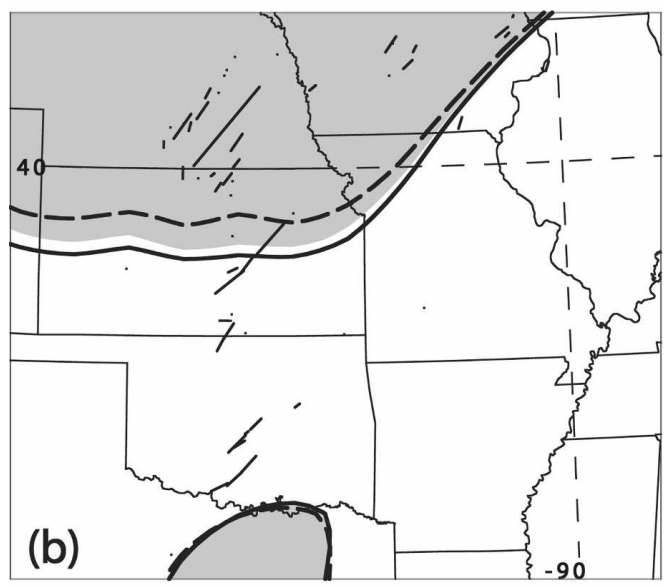

$900313 / 1800$ SREH TC

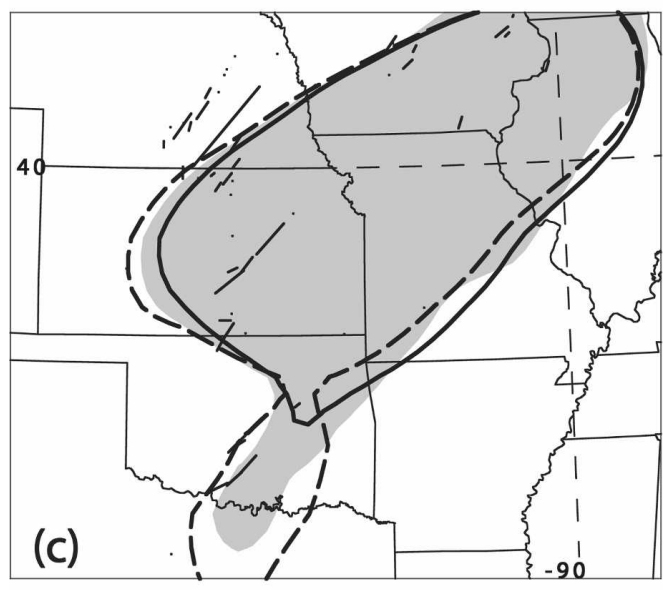

$900313 / 1800 \mathrm{EHITC}$

FIG. 13. Threshold contour maps for (a) CAPE, (b) SREH, and (c) EHI at 1800 UTC 13 Mar 1990. The shaded region encompasses all points where the analyzed parameter value is greater than the threshold contour (except for CAPE, for which the balanced values are used). The dashed and solid contours are threshold contours for AMP and NOPV, respectively. Tornado tracks are overplotted in (a)-(c).
The EHI threshold exhibits more sensitivity to the removal of the SP than to its amplification (Fig. 13c). In the former case, the EHI threshold contour moves eastward across Kansas and northern Oklahoma, bringing it close to the origin of the tornado tracks there. Over southern Oklahoma, the EHI threshold contour "pinches off," receding farther north and east away from the tornado origin points over southern and central Oklahoma. In the AMP experiment, the region enclosed by the EHI contour merely expands to the north and west by $5-15 \mathrm{~km}$. Insofar as the EHI threshold chosen $(\mathrm{EHI}=0.77)$ can be relied upon as a boundary separating environments clearly supportive of significant tornadic supercells from those that also support less intense convection, it is clear that a removal of the SP results in a reduction of the tornadic potential over the southern portion of the outbreak region and moves the regime over central Kansas closer to that boundary. The largest contribution to the reduction in EHI over southern and central Oklahoma northward across central and northern Kansas is from the significant depletion of CAPE induced over that geographical region in going from the unperturbed to the NOPV balanced state (refer to Fig. 13a); the slight gain in SREH (Fig. $13 b)$ over central and northern Kansas is strongly offset by the CAPE reduction. The conclusion stemming from this result is that the existence of the SP was important to the establishment of a large-scale environment supportive of significant tornadic supercells, primarily through responses in CAPE, but that once this threshold was crossed, the precise magnitude of the SP was unimportant.

By 0000 UTC 14 March 1990 the balanced CAPE field (as defined by the CAPE threshold contour in Fig. 14a) had not expanded significantly compared with 1800 UTC (cf. Fig. 13a). However, the geographical corridor possessing analyzed SREH values less than the threshold value at 1800 UTC (i.e., Oklahoma, southern Kansas, the southeastern three quarters of Missouri, and all areas farther east) is completely enclosed by the SREH threshold contour by 0000 UTC (Fig. 14b), except for the region in the vicinity of the surface dryline from western Kansas to northwestern Texas where surface winds are less backed at 0000 UTC (cf. Fig. 13b). As is the case at 1800 UTC, the EHI threshold contour is displaced eastward from its analyzed position to a location close to the tornado origins over Oklahoma and Kansas (Fig. 14c), and there is little change in the EHI contour position for AMP and slightly more for NOPV. Thus, an analysis of convective parameters at 0000 UTC, a time when tornadoes are already in progress, leads to the same conclusion deduced from 

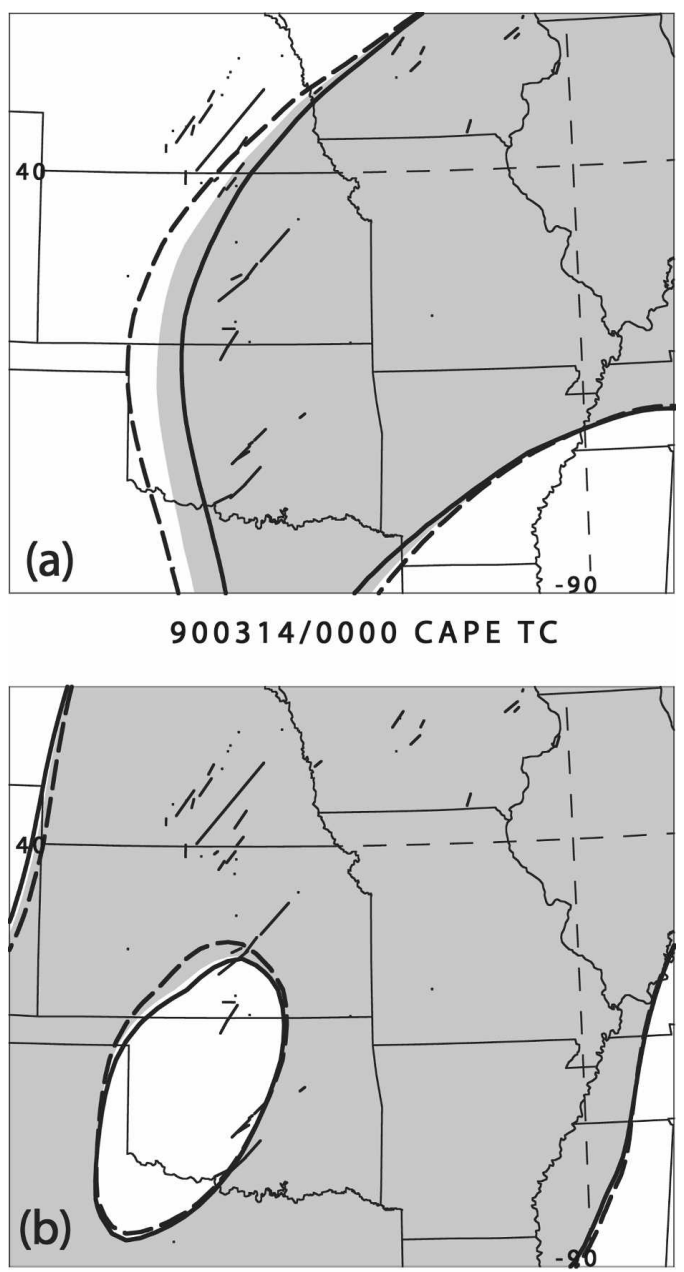

$900314 / 0000$ SREH TC

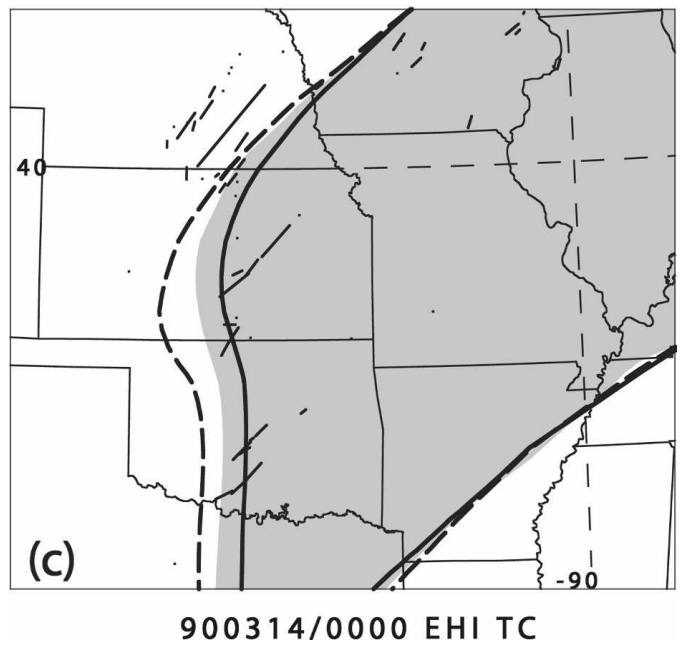

FIG. 14. As in Fig. 13, but at 0000 UTC 14 Mar 1990. the 1800 UTC analysis: if the SP were absent during the afternoon or evening, environmental conditions might become marginally less supportive of tornadic supercells just east of the dryline over Oklahoma and Kansas where CAPE would be substantially reduced. Nonetheless, the environment downstream of the tornado genesis locations still possesses sufficient CAPE, SREH, and a favorable combination of these two parameters (as quantified by EHI) to support the development and sustenance of long-lived rotating convection and likely tornadoes.

\section{Conclusions and implications}

The objective of this research is to apply high-order PV diagnostics to the problem of understanding how upper-tropospheric mobile troughs directly affect the severe convective regime. This regime is defined in terms of physical parameters that are readily computed from the balanced flow variables obtained via inversion of the observed and modified PV distributions. By altering the PV in regions spatially and temporally proximate to a significant convective outbreak, the balanced diagnosis reveals how the convective parameters are affected by the PV modification.

In this paper, the Hesston tornado day (13 March 1990 ) is diagnosed to examine the sensitivity of the severe convective parameter space to changes in the extant PV structure. The flow aloft over the outbreak region featured a subsynoptic-scale cold tropopause anomaly associated with an eastward protrusion of high-PV stratospheric air. The SP is both amplified (AMP) and removed (NOPV), and the resulting new PV distributions inverted to quantify the impact of the PV changes on CAPE, SREH, and EHI. Because the PV modification amplitude is arbitrary, the most important results concern the spatial pattern of the changes to the convective parameters and the kinematic or thermodynamic reasons for those changes.

The balanced CAPE is quite sensitive to the PV alterations in places, with peak CAPE changes of 300 $400 \mathrm{~J} \mathrm{~kg}^{-1}$ produced in response to relatively small and localized PV modifications. CAPE increases are associated with cooling of the temperature profile throughout the mid- and upper troposphere attributable to an increase in the magnitude of the upper-tropospheric PV anomaly. CIN tends to change in the opposite sense, decreasing as midlevel temperatures cool (for PV increases). Nearly opposite changes in CAPE and CIN are found for PV reductions. However, CIN modifications are minimal over the region experiencing the greatest instantaneous CAPE changes. Furthermore, because the SP remains just west of the convective outbreak area, CAPE tends to be most strongly affected 
near the region's western periphery-typically near the dryline.

The relationship between upper-level PV modifications and vertical motion can be summarized in terms of the Trenberth approximation to the forcing for vertical motion (Trenberth 1978): amplifying a trough increases the ascent forced by the trough over the convective region, provided this region is downshear of the trough. The implication of this result is that if an increase in the strength of a trough is large enough, the convective evolution might be dominated by a greater number of storms instead of isolated supercells. The findings gleaned from the Hesston case study suggest that relatively weak modifications to the subsynopticscale PV structure only minimally impact the vertical motion field and therefore are not likely to significantly impact the convective distribution and mode through this mechanism.

Perhaps the most interesting result of the diagnostic analyses is the effect of changing the upper-level PV on the shear parameters. Shear anomalies produced by a given PV modification are centered on the cross-shear flanks of that modification (relative to the background shear vector). Amplifying (reducing) the magnitude of the upper-level PV anomalies in both cases reduces (increases) the SREH downshear of the modification, producing a phase difference of roughly $90^{\circ}$ between the SREH and shear anomalies on the northern flank of the balanced flow anomalies associated with the modification. A consideration of the relationship between the perturbation shear and the background shear vector clarifies the findings: a positive upper-level PV perturbation, such as is produced when an upper-level trough is amplified, will always produce a cyclonic circulation of the perturbation shear vector such that the shear is generally opposed (enhanced) on the trough's cyclonic (anticyclonic) shear side. The opposite is true of a negative upper-level PV perturbation, which is associated with an anticyclonic perturbation shear vector pattern. For both AMP and NOPV, the vertical shear changes in the warm sector are negligibly small.

The SREH is impacted mostly through the alteration of the storm motion vector (SMV), because the lowertropospheric wind profile is generally affected little by PV modifications of the magnitude chosen in both AMP and NOPV. In general, wherever the perturbation shear acts to both weaken and rotate the total shear vector to the left, the SMV will be changed in the same manner and SREH reduced accordingly. Changes in the opposite direction lead to a corresponding increase of SREH. In the AMP and NOPV experiments detailed in section 2, the aforementioned relationship between background and perturbation shear vectors is satisfied downshear of the PV modification, producing reduced SREH there for PV amplifications. This is not the case upshear, but because antecedent buoyancy large enough to support significant convection typically exists both downshear and on the anticyclonic shear side of the upper-tropospheric jet, the SREH and shear changes in those regions are most relevant to the convective regime. Amplifying the SP produces a maximum decrease in SREH of less than $10 \%$ across the northern half of the outbreak region.

The impact of the convective parameter changes on convective mode is inferred by examining how the threshold contours of the parameters vary for a given PV change. The threshold contours themselves are chosen on the basis of the climatology of convective parameters conducted by RB98, and demarcate the boundaries of a region in which a given parameter exceeds the chosen threshold. If a PV modification results in a significant horizontal displacement of a contour or a change in the geographical distribution of the parameter corresponding to that contour, one can infer that the convective outbreak environment is sensitive to the PV change. For the case examined, most of the tornadoes initiate within a background environment characterized by ample CAPE, but only marginal SREH. By 0000 UTC, the entire outbreak region is characterized by substantial values of all convective parameters, except for SREH which is subthreshold along and east of the Oklahoma and southern Kansas dryline. As measured by changes in the EHI at both times examined (1800 and 0000 UTC), neither AMP nor NOPV significantly reduces the tornado threat in any part of the region, except for far southern Oklahoma where the weakest tornadoes of the day occurred.

It is emphasized that the PV modifications examined herein are relatively small, representing the addition or subtraction of subsynoptic-scale shortwaves from the observed flow. The preliminary results discussed above suggest that the impact of small-scale tropopause disturbances on the SCR is not likely to substantively change the convective mode if the background environment (e.g., the environment that exists in the ensemble mean) is already favorable for significant severe convection.

Although the SCR changes were readily related to common aspects of the SCR in the upper and lower troposphere, this has been an individual case study and other events may differ. Furthermore, the analysis here is purely diagnostic and it is possible that as the atmosphere evolves in response to differences in PV, feedbacks and nonlinearities may lead to impacts other than those discussed here. In Part IV, a second severe weather outbreak is diagnosed, in order to determine 
whether the SCR impacts are similar from case to case and whether this instantaneous diagnostic approach yields results compatible with a fully complex numerical simulation.

Acknowledgments. The authors thank Christopher Davis for providing the software used in inverting the $\mathrm{PV}$, as well as for providing invaluable assistance with the use of the prognostic balance equation solver. We are grateful for the insightful comments of the reviewers. This research was supported by the National Science Foundation through Grant ATM-0089906.

\section{REFERENCES}

Bluestein, H. B., and M. L. Weisman, 2000: The interaction of numerically simulated supercells initiated along lines. Mon. Wea. Rev., 128, 3128-3149.

Bosart, L. F., and G. M. Lackmann, 1995: Postlandfall tropical cyclone reintensification in a weakly baroclinic environment: A case study of Hurricane David (September 1979). Mon. Wea. Rev., 123, 3268-3291.

Bunkers, M. J., B. A. Klimowski, J. W. Zeitler, R. L. Thompson, and M. L. Weisman, 2000: Predicting supercell motion using a new hodograph technique. Wea. Forecasting, 15, 61-79.

Craven, J. P., H. E. Brooks, and J. A. Hart, 2002: Baseline climatology of sounding derived parameters associated with deep, moist convection. Preprints, 21st Conf. on Severe Local Storms, San Antonio, TX, Amer. Meteor. Soc., 643-646.

Davies, J. M., and R. H. Johns, 1993: Some wind and instability parameters associated with strong and violent tornadoes. 1. Wind shear and helicity. The Tornado: Its Structure, Dynamics, Prediction, and Hazards, Geophys. Monogr., Vol. 79, Amer. Geophys. Union, 573-582.

, C. A. Doswell, D. F. Burgess, and J. F. Weaver, 1994: Some noteworthy aspects of the Hesston, Kansas, tornado family of 13 March 1990. Bull. Amer. Meteor. Soc., 75, 1007-1017.

Davies-Jones, R., 1984: Streamwise vorticity: The origin of updraft rotation in supercell storms. J. Atmos. Sci., 41, 29913006.

Davis, C. A., and K. A. Emanuel, 1991: Potential vorticity diagnostics of cyclogenesis. Mon. Wea. Rev., 119, 1929-1953.
_ E. D. Grell, and M. A. Shapiro, 1996: The balanced dynamical nature of a rapidly intensifying oceanic cyclone. Mon. Wea. Rev., 124, 3-26.

Fujita, T. T., 1981: Tornadoes and downbursts in the context of generalized planetary scales. J. Atmos. Sci., 38, 1511-1534.

Gold, D. A., and J. W. Nielsen-Gammon, 2008a: Potential vorticity diagnosis of the severe convective regime. Part I: Methodology. Mon. Wea. Rev., 136 1565-1581.

_ and - 2008b: Potential vorticity diagnosis of the severe convective regime. Part IV: Comparison with modeling simulations of the Moore tornado outbreak. Mon. Wea. Rev., 136, 1612-1629.

Hoskins, B. J., M. E. McIntyre, and A. W. Robertson, 1985: On the use and significance of isentropic potential vorticity maps. Quart. J. Roy. Meteor. Soc., 111, 877-946.

Kalnay, E., and Coauthors, 1996: The NCEP/NCAR 40-Year Reanalysis Project. Bull. Amer. Meteor. Soc., 77, 437-471.

Morgan, M. C., and J. W. Nielsen-Gammon, 1998: Using tropopause maps to diagnose midlatitude weather systems. Mon. Wea. Rev., 126, 2555-2579.

Nielsen-Gammon, J. W., and D. A. Gold, 2008: Potential vorticity diagnosis of the severe convective regime. Part II: The impact of idealized PV anomalies. Mon. Wea. Rev., 136, 1582-1592.

Rasmussen, E. N., 2003: Refined supercell and tornado forecast parameters. Wea. Forecasting, 18, 530-535.

—_, and D. O. Blanchard, 1998: A baseline climatology of sounding-derived supercell and tornado forecast parameters. Wea. Forecasting, 13, 1148-1164.

Roebber, P. J., D. M. Schultz, and R. Romero, 2002: Synoptic regulation of the 3 May 1999 tornado outbreak. Wea. Forecasting, 17, 399-429.

Thompson, R. L., R. Edwards, J. A. Hart, K. L. Elmore, and P. M. Markowski, 2003: Close proximity soundings within supercell environments obtained from the Rapid Update Cycle. Wea. Forecasting, 18, 1243-1261.

Thorpe, A. J., 1986: Synoptic-scale disturbances with circular symmetry. Mon. Wea. Rev., 114, 1384-1389.

— static analogy: Ertel-Rossby formulation. Quart. J. Roy. Meteor. Soc., 121, 1477-1495.

Trenberth, K. E., 1978: On the interpretation of the diagnostic quasi-geostrophic omega equation. Mon. Wea. Rev., 106, 131-137. 